\title{
Global sensitivity analysis of n-butanol ignition delay times to thermodynamics class and rate rule parameters
}

\author{
Mireille Hantouche $^{\mathrm{a}}$, S. Mani Sarathy ${ }^{\mathrm{b}}$, Omar M. Knio ${ }^{\mathrm{c}, *}$ \\ ${ }^{a}$ Division of Physical Science and Engineering, King Abdullah University of Science and \\ Technology, Thuwal, Saudi Arabia \\ ${ }^{b}$ King Abdullah University of Science and Technology, Clean Combustion Research \\ Center, Division of Physical Sciences and Engineering, Thuwal, Saudi Arabia \\ ${ }^{c}$ Division of Computer, Electrical, and Mathematical Sciences and Engineering, King \\ Abdullah University of Science and Technology, Thuwal, Saudi Arabia
}

\begin{abstract}
We study the variability in the ignition delay time, $\tau_{i g n}$, of n-butanol due to uncertainty in the enthalpies and entropies of the fuel and fuel radicals. A stoichiometric mixture reacting adiabatically at constant volume is considered, over a range of initial temperatures $(700-1000 \mathrm{~K})$ and pressures (10-80 bar). We develop a thermodynamic class approach to account for the variability in the thermodynamic properties of species of interest, and to define associated uncertainty ranges. To gain insight into the impact of the variability of the thermodynamic properties of individual species, a brute force sensitivity analysis is first performed. The results show that large variations in $\tau_{i g n}$ are mainly due to perturbations in the enthalpies of six species belonging to two thermodynamic classes. A refined 1D analysis is then conducted of the uncertain enthalpies and entropies of these six species. In particular, a complex, nonmonotonic dependence of $\tau_{i g n}$ on species enthalpies is observed, highlighting potential limitations in extrapolating local sensitivity results. The 1D analysis also shows that uncertainties in species entropies have a weaker impact on the variability in $\tau_{i g n}$ than the species enthalpies. A global sensitivity analysis of the impact of thermodynamic class uncertainties is then performed, namely using surrogates constructed using an adaptive pseudo-spectral method. The results indicate that the variability of $\tau_{i g n}$ is dominated by uncertainties in the classes associated with peroxy and hydroperoxide radicals. Lastly, we perform a combined sensitivity analysis of uncertainty in kinetic rates and thermodynamic properties. In particular, the results indicate that uncertainties in thermodynamic properties can in-
\end{abstract}

\footnotetext{
${ }^{*}$ Corresponding author. Email: omar.knio@kaust.edu.sa
} 
duce variabilities in ignition delay time that are as large as those associated with kinetic rate uncertainties.

Keywords: Thermodynamic classes, rate rules, polynomial chaos surrogate, global sensitivity analysis, n-butanol

\section{Introduction}

Building accurate chemical kinetic models depends on reliable kinetic and thermodynamic data. These data are the required inputs for various solvers (Chemkin [1], Cantera [2], TChem [3],...) that enable the numerical simulation of ignition and oxidation phenomena, and provide insights into quantities of interest such as ignition delay time, species evolution, and the impact of mixture compositions. Higher accuracy inputs generally result in better representations and predictions of fuel reactivities. Consequently, many efforts have been placed on accurate determination of rate and thermochemical parameters.

Motivated by this goal, several studies have focused on uncertainty quantification particularly [4-7] to assess sensitivities and to accelerate Bayesian inference studies [8-15]. Most of the work in the literature [16-18] addresses the uncertainty in Arrhenius rate parameters, typically characterized in terms of uncertainty factors (UFs) of pre-exponential parameters. These uncertainties are then propagated to the quantity(ies) of interest (QoI). Several techniques have been developed to examine the impact of uncertain inputs on the QoIs. In particular, polynomial chaos (PC) expansions emerged as a robust tool for accelerating problems with high uncertain input dimensionality through the construction of surrogate models that provide an explicit functional dependence of QoIs in terms of the uncertain inputs. These surrogates are then readily exploited to quantify the sensitivities, and to estimate variance-based Sobol indices [19-23]. Insights on dominant uncertain inputs affecting the sensitivies in the QoIs can then be used in model reduction and parameter calibration [24-26].

In contrast to the fairly well explored uncertainty in reaction rates, less focus has been placed on studying the effect of uncertainties in thermodynamic parameters. As explained by Burcat and Ruscic in [27], this may be due to the misconceptions that thermodynamic data are readily available and accurate. Bromly et al. [28] is one of the early works in the literature addressing thermodynamic uncertainty in NO-sensitised oxidation of methane by perturbing species heats of formation and entropies. Later work by Turanyi et al. [29] studied the effect of the uncertainty in kinetic and thermodynamic data on the structure of the methane flame using single parameter sensitivi- 
ties. Following a similar approach to [29], Zsely et al. [30] analyzed the effect of these uncertainties on hydrogen and carbon monoxide oxidation. In [31] local and global uncertainty analyses of a methane flame model are conducted. Subsequent work [32] included a global sensitivity analysis, to quantify the impact of uncertainty in kinetic rate parameters and enthalpies of formation on NO production during methane combustion. In another study, vom Lehn et al. [33] considered uncertainty in the heat capacities, enthalpies of formation and standard entropies of species, and analyzed their effects on ignition characteristics of diethyl ether. They performed a local sensitivity analysis, based on a brute force approach, followed by uncertainty minimization using polynomial chaos expansions (MUM-PCE) and optimization. Sensitivity and uncertainty analyses were used in [34] to analyze the impact of kinetic and thermochemical properties on ignition of diethyl ether and to optimize the kinetic model. Thermochemical uncertainty was analyzed in [35] by perturbing the group values of the group additivity method and studying its impact on ignition predictions of the oxidation of 2-methylhexane.

Briefly, work in the literature is still limited when it comes to, first, the combined effects of uncertainties of different thermodynamic properties of different species, and also the combined effects of uncertainties in kinetic rates and thermodynamic properties. Hence, this work aims to address these issues. We focus on exploring the effect of uncertainties in thermodynamic properties on ignition delay time, $\tau_{i g n}$, for constant volume n-butanol simulations at stoichiometry $\phi=1$ and over a range of initial temperatures and pressures. The uncertainties are propagated through the molar enthalpies and entropies of the fuel and fuel radicals involved in the dominant reactions identified from our previous work [36]. We develop a thermodynamic class approach to segregate the species of interest and follow an elaborate process to define associated uncertainties. To define the range of variability of individual species enthalpy and entropy, we assume that these thermodynamic properties of the species within the same class are uncertain but perfectly correlated. Next, peak coefficients of variations, $\mathrm{CoV}_{\text {peak }}$, are assigned to each thermodynamic class by relying on data for reference species from [37], and uncertainty ranges for the molar enthalpies and entropies of each species are accordingly defined. Once the uncertainty ranges are defined, we start with a local sensitivity analysis. This is followed by a forward uncertainty quantification study for $\tau_{i g n}$ due to uncertainty in thermodynamic classes. The surrogates from the forward UQ are exploited for sensitivity study. Then, we extend our analysis to include a combined uncertainty in reaction kinetics and thermodynamic properties and study its impact on the variability in $\tau_{i g n}$.

This paper is organized as follows. In section 2 , the thermodynamic class approach is outlined. In section 3 , the brute force sensitivity analysis of $\tau_{i g n}$ 
due to uncertainty in thermodynamic properties of individual species is carried out. In section 4, we present the results of the global sensitivity analysis of $\tau_{i g n}$ due to uncertainties in the enthalpies and entropies of thermodynamic classes. Lastly, a combined uncertainty analysis of reaction kinetics and thermodynamic properties uncertainties on the variability in $\tau_{i g n}$ is explored in section 5. The main takeaways from this work are summarized in section 6 .

\section{Methodology}

In order to gain insight into the importance of uncertainties in thermodynamic properties on the ignition delay time, we begin by studying the effect of the variabilities in the enthalpies and entropies of individual species associated with thermodynamic classes, introduced in the following section. To this end, we consider the combustion of n-butanol in air at constant volume and stoichiometry $\phi=1$ for various initial conditions of temperature and pressure.

We begin by summarizing the representation of species enthalpies and entropies in a reaction kinetics numerical model. Next, we introduce the various thermodynamic classes. The relation between the uncertain parameters and the classes is then detailed. The setup utilized to perform the analysis of ignition delay times is then presented, followed by a brief description of the surrogate construction from which we obtain first and total order sensitivity indices.

\subsection{Molar Enthalpy and Entropy}

In a reaction kinetics model [3], the molar enthalpy $\left(H_{f}\right)$ and entropy $(S)$ for a mixture are given by :

$$
H_{f}=\sum_{k=1}^{N_{\text {spec }}} X_{k} H_{f_{k}}, \quad S=\sum_{k=1}^{N_{\text {spec }}} X_{k} S_{k}
$$

where the subscript $k$ indexes the individual species, $N_{\text {spec }}$ is the total number of species in the mixture, and $X_{k}$ is the mole fraction of species $k$. The standard-state thermodynamic properties for individual species are computed using the NASA polynomials [38] :

$$
\begin{gathered}
\frac{H_{f_{k}}}{R}=T\left(a_{0, k}+T\left(\frac{a_{1, k}}{2}+T\left(\frac{a_{2, k}}{3}+T\left(\frac{a_{3, k}}{4}+\frac{a_{4, k}}{5} T\right)\right)\right)\right)+a_{5, k} \\
\frac{S_{k}}{R}=a_{0, k} \ln T+T\left(a_{1, k}+T\left(\frac{a_{2, k}}{2}+T\left(\frac{a_{3, k}}{3}+\frac{a_{4, k}}{4} T\right)\right)\right)+a_{6, k}
\end{gathered}
$$


where $R$ is the universal gas constant and $T$ is the temperature in K. Generally, the NASA polynomials are fitted in established and well defined temperature ranges. There are fourteen polynomial fitting coefficients for the thermodynamic data, seven coefficients for each of two temperature ranges, the low and high temperature ranges as specified in the thermodynamic data file.

\subsection{Thermodynamics classes}

Based on the results from our previous study on the global sensitivity analysis of n-butanol reaction kinetics [36], we identified that ignition delay time is sensitive to variations in four dominant rate rules, namely, H-atom abstraction from the fuel (reaction class 2), addition of $\mathrm{O}_{2}$ to fuel radicals $\left(\mathrm{R}+\mathrm{O}_{2}=\mathrm{ROO}\right)$ (reaction class 11$)$, ROO radical isomerization $(\mathrm{ROO}=$ QOOH) including Waddington type reaction mechanism (reaction class 15) and concerted eliminations (reaction class 16). (For convenience, the reaction classes are reproduced in Appendix A.) The fuel and fuel radicals involved in these four dominant reaction classes are identified, and amounting to 54 species of interest. Among these species, several are structural isomers.

We are interested in studying the sensitivity of the ignition delay time to variations in the enthalpies and entropies of these species. Hence, we segregated these 54 species into five classes based on their chemical structure.

As listed in Table 1 below, the thermodynamic classes, and the species corresponding to each class, are as follows:

1. Alcohol: $\mathrm{nC}_{4} \mathrm{H}_{9} \mathrm{OH}$

2. Alkoxy radicals: $\mathrm{C}_{4} \mathrm{H}_{8} \mathrm{OH}-1 \mathrm{O}, \mathrm{C}_{4} \mathrm{H}_{8} \mathrm{OH}-2 \mathrm{O}, \mathrm{C}_{4} \mathrm{H}_{8} \mathrm{OH}-3 \mathrm{O}, \mathrm{C}_{4} \mathrm{H}_{8} \mathrm{OH}-4 \mathrm{O}$ and $\mathrm{pC}_{4} \mathrm{H}_{9} \mathrm{O}$

3. Hydroxy alkyl radicals: $\mathrm{C}_{4} \mathrm{H}_{8} \mathrm{OH}-1, \mathrm{C}_{4} \mathrm{H}_{8} \mathrm{OH}-2, \mathrm{C}_{4} \mathrm{H}_{8} \mathrm{OH}-3$ and $\mathrm{C}_{4} \mathrm{H}_{8} \mathrm{OH}-4$

4. Peroxy radicals: $\mathrm{C}_{4} \mathrm{H}_{7} \mathrm{OH}-1 \mathrm{OOH}-2 \mathrm{O}_{2}, \mathrm{C}_{4} \mathrm{H}_{7} \mathrm{OH}-1 \mathrm{OOH}-3 \mathrm{O}_{2}$, $\mathrm{C}_{4} \mathrm{H}_{7} \mathrm{OH}-1 \mathrm{OOH}-4 \mathrm{O}_{2}, \mathrm{C}_{4} \mathrm{H}_{7} \mathrm{OH}-2 \mathrm{OOH}-1 \mathrm{O}_{2}, \mathrm{C}_{4} \mathrm{H}_{7} \mathrm{OH}-2 \mathrm{OOH}-3 \mathrm{O}_{2}, \mathrm{C}_{4} \mathrm{H}_{7} \mathrm{OH}-$ $2 \mathrm{OOH}-4 \mathrm{O}_{2}, \mathrm{C}_{4} \mathrm{H}_{7} \mathrm{OH}-3 \mathrm{OOH}-1 \mathrm{O}_{2}, \mathrm{C}_{4} \mathrm{H}_{7} \mathrm{OH}-3 \mathrm{OOH}-2 \mathrm{O}_{2}, \mathrm{C}_{4} \mathrm{H}_{7} \mathrm{OH}-3 \mathrm{OOH}-$ $4 \mathrm{O}_{2}, \mathrm{C}_{4} \mathrm{H}_{7} \mathrm{OH}-4 \mathrm{OOH}-1 \mathrm{O}_{2}, \mathrm{C}_{4} \mathrm{H}_{7} \mathrm{OH}-4 \mathrm{OOH}-2 \mathrm{O}_{2}, \mathrm{C}_{4} \mathrm{H}_{7} \mathrm{OH}-4 \mathrm{OOH}-3 \mathrm{O}_{2}$, $\mathrm{C}_{4} \mathrm{H}_{8} \mathrm{OH}-1 \mathrm{O}_{2}, \mathrm{C}_{4} \mathrm{H}_{8} \mathrm{OH}-2 \mathrm{O}_{2}, \mathrm{C}_{4} \mathrm{H}_{8} \mathrm{OH}-3 \mathrm{O}_{2}$, and $\mathrm{C}_{4} \mathrm{H}_{8} \mathrm{OH}-4 \mathrm{O}_{2}$

5. Hydroperoxide radicals: $\mathrm{C}_{4} \mathrm{H}_{7} \mathrm{OH}-1 \mathrm{OOH}-2, \mathrm{C}_{4} \mathrm{H}_{7} \mathrm{OH}-1 \mathrm{OOH}-3, \mathrm{C}_{4} \mathrm{H}_{7} \mathrm{OH}-$ $1 \mathrm{OOH}-4, \mathrm{C}_{4} \mathrm{H}_{7} \mathrm{OH}-2 \mathrm{OOH}-1, \mathrm{C}_{4} \mathrm{H}_{7} \mathrm{OH}-2 \mathrm{OOH}-3, \mathrm{C}_{4} \mathrm{H}_{7} \mathrm{OH}-2 \mathrm{OOH}-4, \mathrm{C}_{4} \mathrm{H}_{7} \mathrm{OH}-$ $3 \mathrm{OOH}-1, \mathrm{C}_{4} \mathrm{H}_{7} \mathrm{OH}-3 \mathrm{OOH}-2, \mathrm{C}_{4} \mathrm{H}_{7} \mathrm{OH}-3 \mathrm{OOH}-4, \mathrm{C}_{4} \mathrm{H}_{7} \mathrm{OH}-4 \mathrm{OOH}-1, \mathrm{C}_{4} \mathrm{H}_{7} \mathrm{OH}-$ $4 \mathrm{OOH}-2, \mathrm{C}_{4} \mathrm{H}_{7} \mathrm{OH}-4 \mathrm{OOH}-3, \mathrm{C}_{4} \mathrm{H}_{8} \mathrm{OH}-1 \mathrm{O}_{2} \mathrm{H}, \mathrm{C}_{4} \mathrm{H}_{8} \mathrm{OH}-2 \mathrm{O}_{2} \mathrm{H}, \mathrm{C}_{4} \mathrm{H}_{8} \mathrm{OH}-$ $3 \mathrm{O}_{2} \mathrm{H}, \mathrm{C}_{4} \mathrm{H}_{8} \mathrm{OH}-4 \mathrm{O}_{2} \mathrm{H}, \mathrm{C}_{4}$ OHket1-2, $\mathrm{C}_{4}$ OHket1-3, $\mathrm{C}_{4}$ OHket1-4, $\mathrm{C}_{4}$ OHket21, $\mathrm{C}_{4}$ OHket2-3, $\mathrm{C}_{4}$ OHket2-4, $\mathrm{C}_{4}$ OHket3-1, $\mathrm{C}_{4}$ OHket3-2, $\mathrm{C}_{4}$ OHket3-4, $\mathrm{C}_{4}$ OHket4-1, $\mathrm{C}_{4}$ OHket4-2 and $\mathrm{C}_{4}$ OHket4-3 
When considering uncertainty in the thermodynamic classes, we assume that species within the same class have uncertain but perfectly correlated properties. A pair of independent canonical random variables, $\xi^{H_{f}}$ and $\xi^{S}$, is then associated with each class; $\xi_{i}^{H_{f}}$ parametrizes the uncertainty in the enthalpy of class $i$, whereas $\xi_{i}^{S}$ parametrizes the uncertainty in its entropy.

\subsection{Uncertain Inputs}

The thermodynamic properties of many species are measured and collected in various databases. For instance, an exhaustive library of thermodynamic properties can be found in JANAF Thermochemical Tables [39], NIST Database [40], Active Thermochemical Tables [41, 42], Third Millennium Thermodynamics Database [43]. Nonetheless, there remain numerous key species, appearing in various combustion mechanisms, for which thermodynamic data are not available. Hence, the group additivity (GA) method pioneered by Benson $[44,45]$ is one of the prominent techniques used to estimate these thermodynamic properties. Briefly, the GA method explores the thermodynamic functions that depend on the nature of each atom in a molecule, and the nature of each of their bonding partners. The idea is then to divide each molecule into well defined groups with an empirical value assigned to them. Each group makes a contribution to the thermodynamic functions of the molecule, and this contribution is added to the contribution of the molecule's symmetry, number of rotors and interactions. THERM [46] software package is one of the tools that uses this concept of GA to estimate the standard state thermodynamic properties of species. These estimated properties are uncertain [27] and are given as polynominal fits presented as NASA polynomials in section 2.1. Consequently, the fits are uncertain as well because they are obtained from uncertain estimated properties.

Since we aim in this study to propagate the uncertainty in the thermodynamic properties to our QoI, we model the uncertainty in the molar enthalpies and entropies as temperature independent. Moreover, bearing in mind that the fits are uncertain, this leads to describing this uncertainty as an uncertainty in the constant coefficients of the NASA polynomials, specifically $a_{5, k}$ and $a_{6, k}$, at both the low and high temperature range, with the index $k$ going from 1 to 54 in the order of species listed above.

In order to determine the suitable uncertain ranges, we rely on reference species from [37]. We associate, to each of the five classes identified in section 2.2, one or more reference species from [37]. These reference species, corresponding to each class, are as follows:

1. Alcohol: ethanol, n-propanol and iso-propanol

2. Alkoxy radicals: n-propoxy and iso-propoxy 
3. Hydroxy alkyl radicals: ethyl, n-propyl, iso-propyl, n-butyl, s-butyl, iso-butyl and tert-butyl

4. Peroxy radicals: ethyl peroxy, n-propyl peroxy, iso-propyl peroxy and n-butyl peroxy

5. Hydroperoxide radicals: ethyl hydroperoxide, n-propyl hydroperoxide, iso-propyl hydroperoxide and n-butyl hydroperoxide

From [37] we extract three values for each reference species: the standard deviation, recommended enthalpy of formation and GA recommended enthalpy of formation. Then, we calculate two coefficients of variation (CoVs), one associated with the recommended enthalpy and the second with the GA recommended enthalpy. Among all CoVs calculated from the reference species belonging to the same class, we take the maximum $\mathrm{CoV}$ value, which we denote as $\mathrm{CoV}_{\text {peak }}$. Using $\mathrm{CoV}_{\text {peak }}$, we go back to our thermodynamic classes, and we calculate the corresponding standard deviation of the molar enthalpy for each species of interest, denoted by $\sigma_{k}^{H_{f}}$. This $\sigma_{k}^{H_{f}}$ is obtained by calculating $\sigma_{k}^{H_{f}}=\mathrm{CoV}_{\text {peak }} \times \mu_{k}$. The mean, $\mu_{k}$, here is the enthalpy of formation of the species of interest at $298.15 \mathrm{~K}$. An upper bound of $10 \mathrm{kcal} \cdot \mathrm{mol}^{-1}$ on $\sigma_{k}^{H_{f}}$ is imposed specifically for species belonging to the alkoxy, peroxy and hydroperoxide radicals classes. Now, we have uncertain intervals for our uncertain properties, the enthalpies of our individual species of interest. And since these ranges are temperature independent, we can translate the standard deviation of the molar enthalpy to a standard deviation of the constant coefficient $a_{5, k}$ given in Table 1 and is referred to as $\sigma_{a_{5, k}}$. We therefore convert the $\mathrm{kcal} \cdot \mathrm{mol}^{-1}$ to $\mathrm{K}$ for $\sigma_{a_{5, k}}$ and $\mathrm{cal} \cdot \mathrm{K}^{-1} \cdot \mathrm{mol}^{-1}$ to a unitless $\sigma_{a_{6, k}}$ as presented in Table 1. The same procedure is followed for the calculation of $\sigma_{k}^{S}$ and $\sigma_{a_{6, k}}$ the corresponding standard deviation to the entropy constant coefficient $a_{6, k}$.

The uncertainty in the coefficients $a_{5, k}$ and $a_{6, k}$ for species $k$ can be expressed as follows:

$$
a_{5, k}=a_{5, k}^{0}+\sigma_{a_{5, k}} \xi_{i}^{H_{f}}
$$

and

$$
a_{6, k}=a_{6, k}^{0}+\sigma_{a_{6, k}} \xi_{i}^{S}
$$

where $a_{5, k}^{0}$ and $a_{6, k}^{0}$ are the nominal values, as given in [47], of the constant coefficients of the NASA polynomials (equations 2 and 3, respectively) for species $k, \sigma_{a_{5, k}}$ and $\sigma_{a_{6, k}}$ are the standard deviations (presented in Table 1), $\xi_{i}^{H_{f}}$ and $\xi_{i}^{S}$ are the pair of canonical random variables for enthalpy and entropy of the class $i$ to which species $k$ belongs, uniformly distributed over $[-1,1]$, and $a_{5, k}$ and $a_{6, k}$ are the perturbed values corresponding to $\xi_{i}^{H_{f}}$ and 
$\xi_{i}^{S}$ respectively. All species $(k)$ belonging to the same thermodynamic class $(i)$ are perturbed with the same canonical random variable.

\begin{tabular}{|c|c|c|c|c|}
\hline Thermodynamic Class & Species No & Species Name & $\sigma_{a_{5, k}}(\mathrm{~K})$ & $\sigma_{a_{6, k}}$ \\
\hline 1. Alcohol & 1 & $\mathrm{nC}_{4} \mathrm{H}_{9} \mathrm{OH}$ & 70.67 & 0.2942 \\
\hline \multirow[t]{5}{*}{ 2. Alkoxy radicals } & 2 & $\mathrm{C}_{4} \mathrm{H}_{8} \mathrm{OH}-1 \mathrm{O}$ & 5032.19 & 0.873 \\
\hline & 3 & $\mathrm{C}_{4} \mathrm{H}_{8} \mathrm{OH}-2 \mathrm{O}$ & 5032.19 & 0.877 \\
\hline & 4 & $\mathrm{C}_{4} \mathrm{H}_{8} \mathrm{OH}-3 \mathrm{O}$ & 5032.19 & 0.887 \\
\hline & 5 & $\mathrm{C}_{4} \mathrm{H}_{8} \mathrm{OH}-4 \mathrm{O}$ & 5032.19 & 0.906 \\
\hline & 6 & $\mathrm{pC}_{4} \mathrm{H}_{9} \mathrm{O}$ & 1973.52 & 0.807 \\
\hline \multirow[t]{4}{*}{ 3. Hydroxy alkyl radicals } & 7 & $\mathrm{C}_{4} \mathrm{H}_{8} \mathrm{OH}-1$ & 1219.03 & 1.101 \\
\hline & 8 & $\mathrm{C}_{4} \mathrm{H}_{8} \mathrm{OH}-2$ & 1041.72 & 1.147 \\
\hline & 9 & $\mathrm{C}_{4} \mathrm{H}_{8} \mathrm{OH}-3$ & 1041.72 & 1.147 \\
\hline & 10 & $\mathrm{C}_{4} \mathrm{H}_{8} \mathrm{OH}-4$ & 898.91 & 1.134 \\
\hline \multirow[t]{16}{*}{ 4. Peroxy radicals } & 11 & $\mathrm{C}_{4} \mathrm{H}_{7} \mathrm{OH}-1 \mathrm{OOH}-2 \mathrm{O}_{2}$ & 5032.19 & 1.906 \\
\hline & 12 & $\mathrm{C}_{4} \mathrm{H}_{7} \mathrm{OH}-1 \mathrm{OOH}-3 \mathrm{O}_{2}$ & 5032.19 & 1.906 \\
\hline & 13 & $\mathrm{C}_{4} \mathrm{H}_{7} \mathrm{OH}-1 \mathrm{OOH}-4 \mathrm{O}_{2}$ & 5032.19 & 1.951 \\
\hline & 14 & $\mathrm{C}_{4} \mathrm{H}_{7} \mathrm{OH}-2 \mathrm{OOH}-1 \mathrm{O}_{2}$ & 5032.19 & 1.906 \\
\hline & 15 & $\mathrm{C}_{4} \mathrm{H}_{7} \mathrm{OH}-2 \mathrm{OOH}-3 \mathrm{O}_{2}$ & 5032.19 & 1.914 \\
\hline & 16 & $\mathrm{C}_{4} \mathrm{H}_{7} \mathrm{OH}-2 \mathrm{OOH}-4 \mathrm{O}_{2}$ & 5032.19 & 1.959 \\
\hline & 17 & $\mathrm{C}_{4} \mathrm{H}_{7} \mathrm{OH}-3 \mathrm{OOH}-1 \mathrm{O}_{2}$ & 5032.19 & 1.906 \\
\hline & 18 & $\mathrm{C}_{4} \mathrm{H}_{7} \mathrm{OH}-3 \mathrm{OOH}-2 \mathrm{O}_{2}$ & 5032.19 & 1.914 \\
\hline & 19 & $\mathrm{C}_{4} \mathrm{H}_{7} \mathrm{OH}-3 \mathrm{OOH}-4 \mathrm{O}_{2}$ & 5032.19 & 1.959 \\
\hline & 20 & $\mathrm{C}_{4} \mathrm{H}_{7} \mathrm{OH}-4 \mathrm{OOH}-1 \mathrm{O}_{2}$ & 5032.19 & 1.951 \\
\hline & 21 & $\mathrm{C}_{4} \mathrm{H}_{7} \mathrm{OH}-4 \mathrm{OOH}-2 \mathrm{O}_{2}$ & 5032.19 & 1.959 \\
\hline & 22 & $\mathrm{C}_{4} \mathrm{H}_{7} \mathrm{OH}-4 \mathrm{OOH}-3 \mathrm{O}_{2}$ & 5032.19 & 1.959 \\
\hline & 23 & $\mathrm{C}_{4} \mathrm{H}_{8} \mathrm{OH}-1 \mathrm{O}_{2}$ & 5032.19 & 1.634 \\
\hline & 24 & $\mathrm{C}_{4} \mathrm{H}_{8} \mathrm{OH}-2 \mathrm{O}_{2}$ & 5032.19 & 1.642 \\
\hline & 25 & $\mathrm{C}_{4} \mathrm{H}_{8} \mathrm{OH}-3 \mathrm{O}_{2}$ & 5032.19 & 1.642 \\
\hline & 26 & $\mathrm{C}_{4} \mathrm{H}_{8} \mathrm{OH}-4 \mathrm{O}_{2}$ & 5032.19 & 1.687 \\
\hline \multirow[t]{11}{*}{ 5. Hydroperoxide radicals } & 27 & $\mathrm{C}_{4} \mathrm{H}_{7} \mathrm{OH}-1 \mathrm{OOH}-2$ & 3289.70 & 1.197 \\
\hline & 28 & $\mathrm{C}_{4} \mathrm{H}_{7} \mathrm{OH}-1 \mathrm{OOH}-3$ & 3289.70 & 1.197 \\
\hline & 29 & $\mathrm{C}_{4} \mathrm{H}_{7} \mathrm{OH}-1 \mathrm{OOH}-4$ & 3119.14 & 1.185 \\
\hline & 30 & $\mathrm{C}_{4} \mathrm{H}_{7} \mathrm{OH}-2 \mathrm{OOH}-1$ & 2855.24 & 1.202 \\
\hline & 31 & $\mathrm{C}_{4} \mathrm{H}_{7} \mathrm{OH}-2 \mathrm{OOH}-3$ & 2855.24 & 1.202 \\
\hline & 32 & $\mathrm{C}_{4} \mathrm{H}_{7} \mathrm{OH}-2 \mathrm{OOH}-4$ & 2684.67 & 1.190 \\
\hline & 33 & $\mathrm{C}_{4} \mathrm{H}_{7} \mathrm{OH}-3 \mathrm{OOH}-1$ & 2855.24 & 1.202 \\
\hline & 34 & $\mathrm{C}_{4} \mathrm{H}_{7} \mathrm{OH}-3 \mathrm{OOH}-2$ & 2855.24 & 1.202 \\
\hline & 35 & $\mathrm{C}_{4} \mathrm{H}_{7} \mathrm{OH}-3 \mathrm{OOH}-4$ & 2684.67 & 1.190 \\
\hline & 36 & $\mathrm{C}_{4} \mathrm{H}_{7} \mathrm{OH}-4 \mathrm{OOH}-1$ & 2632.54 & 1.233 \\
\hline & 37 & $\mathrm{C}_{4} \mathrm{H}_{7} \mathrm{OH}-4 \mathrm{OOH}-2$ & 2632.54 & 1.233 \\
\hline
\end{tabular}




\begin{tabular}{|llll|}
38 & $\mathrm{C}_{4} \mathrm{H}_{7} \mathrm{OH}-4 \mathrm{OOH}-3$ & 2632.54 & 1.233 \\
39 & $\mathrm{C}_{4} \mathrm{H}_{8} \mathrm{OH}-1 \mathrm{O}_{2} \mathrm{H}$ & 5032.19 & 1.147 \\
40 & $\mathrm{C}_{4} \mathrm{H}_{8} \mathrm{OH}-2 \mathrm{O}_{2} \mathrm{H}$ & 5032.19 & 1.152 \\
41 & $\mathrm{C}_{4} \mathrm{H}_{8} \mathrm{OH}-3 \mathrm{O}_{2} \mathrm{H}$ & 5032.19 & 1.152 \\
42 & $\mathrm{C}_{4} \mathrm{H}_{8} \mathrm{OH}-4 \mathrm{O}_{2} \mathrm{H}$ & 5032.19 & 1.184 \\
43 & $\mathrm{C}_{4}$ OHket1-2 & 5032.19 & 1.094 \\
44 & $\mathrm{C}_{4}$ OHket1-3 & 5032.19 & 1.106 \\
45 & $\mathrm{C}_{4}$ OHket1-4 & 5032.19 & 1.137 \\
46 & $\mathrm{C}_{4}$ OHket2-1 & 5032.19 & 1.211 \\
47 & $\mathrm{C}_{4}$ OHket2-3 & 5032.19 & 1.209 \\
48 & $\mathrm{C}_{4}$ OHket2-4 & 5032.19 & 1.252 \\
49 & $\mathrm{C}_{4}$ OHket3-1 & 5032.19 & 1.211 \\
50 & $\mathrm{C}_{4}$ OHket3-2 & 5032.19 & 1.205 \\
51 & $\mathrm{C}_{4}$ OHket3-4 & 5032.19 & 1.244 \\
52 & $\mathrm{C}_{4}$ OHket4-1 & 5032.19 & 1.224 \\
53 & $\mathrm{C}_{4}$ OHket4-2 & 5032.19 & 1.229 \\
54 & $\mathrm{C}_{4}$ OHket4-3 & 5032.19 & 1.217 \\
\hline
\end{tabular}

Table 1: $\sigma_{a_{5, k}}(\mathrm{~K})$ and $\sigma_{a_{6, k}}$ for the 54 species of interest belonging to the five thermodynamic classes. The index $k$ runs from 1 to 54 in the order of species that is listed.

\subsection{Simulations and QoI}

We focus on the combustion of n-butanol at constant volume and stoichiometry $(\phi=1)$ with various initial conditions of temperature and pressure. The base mechanism of the chemical model for n-butanol is adapted from [47]. The evolution of temperature, pressure and species mole fractions are simulated using TChem [3].

Our primary quantity of interest here is $\tau_{i g n}$ and it is calculated as the point in time at which the maximum rate of change of temperature occurs, in a similar fashion to what was presented in [36], i.e.

$$
\tau_{\text {ign }}=\underset{\tau}{\arg \max } \frac{d T}{d t}(\tau)
$$

Our study is conducted over a range of intermediate to high intial temperatures, $700 \mathrm{~K} \leqslant \mathrm{~T}_{0} \leqslant 1000 \mathrm{~K}$, and low to high initial pressures, $10 \mathrm{bar} \leqslant$ $\mathrm{p}_{0} \leqslant 80$ bar.

\subsection{Surrogate Construction}

We rely on the adaptive pseudo-spectral projection (aPSP) technique [15, 48-54] to construct our surrogate models of $\tau_{i g n}$ in terms of our canonical 
random variables with the functional dependence of $\tau_{i g n}$ on $\xi$ expressed in series form as:

$$
F(\boldsymbol{\xi})=\sum_{k=0}^{P} c_{k} \Psi_{k}(\boldsymbol{\xi})
$$

where $\Psi_{k}$ are orthogonal functionals of the random variables, $c_{k}$ are the series coefficients, and $P+1$ is the size of the truncated basis. A Smolyak sparse grid based on Gauss-Patterson-Kronrod rule is used, and adaptive grid refinement is performed until a user defined tolerance in the representation is achieved.

In section 5 below, we focus on the combined effects of uncertainty in the dominant reaction rates obtain from [36] and thermodynamic classes on $\tau_{i g n}$. A functional representation of $\tau_{i g n}$ in terms of the canonical germ $\xi$ parameterizing the rate rules and the thermodynamic classes is obtained using a regularized regression approach. Specifically, a random sampling of $\xi$ is performed and LASSO methodology is used. The LASSO regression, as described in [55-59], is based on solving the the following problem:

$$
\min _{\beta_{0}, \beta}\left(\frac{1}{2 N} \sum_{i=1}^{N}\left(y_{i}-\beta_{0}-x_{i}^{T} \beta\right)^{2}+\lambda \sum_{j=1}^{p}\left|\beta_{j}\right|\right),
$$

where $N$ is the number of observations, $y_{i}$ is the response vector at observations $i, x_{i}$ is data, a vector of $p$ values at observation $i, \lambda$ is a nonnegative regularization parameter that is optimized by the LASSO regression algorithm. The parameters $\beta_{0}$ and $\beta$ are a scalar and a vector of length $p$, respectively. A 10-fold cross-validation to mitigate overfitting in our model is applied.

The two positional parameters provided for the routine are the projection matrix of our 10 dimensional stochastic space calculated for different user specified orders [48] and $y_{i}$ the ignition delay time vector obtained from the forward TCHEM runs. The LASSO algorithm yields the regularized leastsquare regression coefficients of the model.

\section{Sensitivity Analysis of Individual Species}

We perform a brute force sensitivity analysis to investigate the variability of ignition delay time of n-butanol combustion in air due to uncertainty in the enthalpies and entropies of individual species belonging to the thermodynamics classes introduced in section 2.2. This analysis is carried out in a two-fold fashion. We begin by separately perturbing, one at a time, each enthalpy and each entropy of our 54 species of interest. We find that the largest variability in $\tau_{i g n}$ is due to perturbations in the properties of six dominant species. Following this observation, we proceed by exploring a finely 
discretized range of uncertain enthalpies and entropies for each of these six prominent species.

\subsection{Brute Force Sensitivity Analysis of Individual Species}

The brute force analysis of $\tau_{i g n}$ to uncertainty in the enthalpies and entropies of the individual species is carried at stochiometric conditions $(\phi=1)$ for a range of temperatures, $\mathrm{T}_{0}=\{700,800,900,1000\}(\mathrm{K})$, and pressures, $\mathrm{p}_{0}=\{10,20,40,80\}$ (bar).

The brute force analysis consists of perturbing the enthalpy and entropy for the individual species, one at a time, by $\pm \sigma_{a_{5, k}}$ and $\pm \sigma_{a_{6, k}}$, respectively. For each perturbation, and every initial condition, a TChem simulation is performed and $\tau_{i g n}$ is calculated as described in section 2.4. In other words, the analysis is such that the large-amplitude positive and negative perturbations in the parameters respectively correspond to the right and left extremities of the uncertainty ranges considered.

We estimate the relative variation of ignition delay time as a sensitivity measure. The relative variation provides insights into the increase or decrease in $\tau_{i g n}$ over the range of variation of enthalpies and entropies as a percentage of the nominal value of $\tau_{i g n}$. The relative variation is calculated as follows:

$$
\text { Relative Variation }=\frac{\tau-\tau_{0}}{\tau_{0}} \times 100 \%
$$

where $\tau_{0}$ is the value of the ignition delay time obtained using nominal entries of the thermodynamic properties and $\tau$ is the value of the ignition delay time obtained after perturbing the enthalpies and entropies of each of the species of interest independently.

Fig. 1 shows the relative variation of $\tau_{i g n}$ due to perturbations in enthalpies and Fig. 2 represents the variations in $\tau_{i g n}$ due to perturbations in entropies for a stoichiometric mixture at $\mathrm{T}_{0}=800 \mathrm{~K}$ and $\mathrm{p}_{0}=\{10,20,40$, $80\}$ bar. Each figure contains two subplots representing the negative and positive perturbations in enthalpies and entropies. 

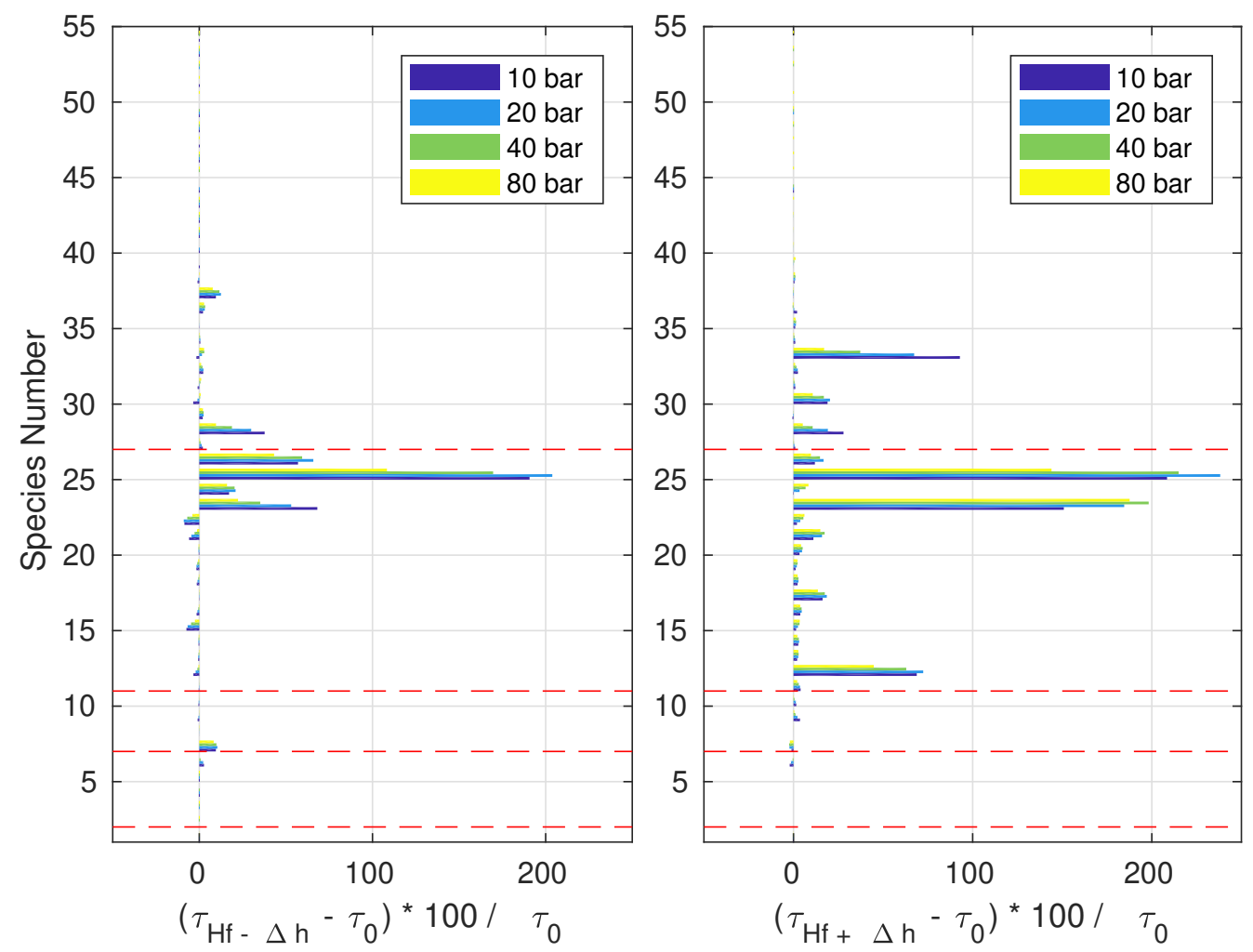

Figure 1: Variation of the ignition delay time with species enthalpies. The results are shown for a stoichiometric mixture $(\phi=1)$ at $\mathrm{T}_{0}=800 \mathrm{~K}$ and $\mathrm{p}_{0}=\{10,20,40,80\}$ bar. The left figure shows the variation of $\tau_{i g n}$ due to a negative perturbation in the enthalpy. The right figure shows the variation of $\tau_{i g n}$ due to a positive perturbation in the enthalpy. 

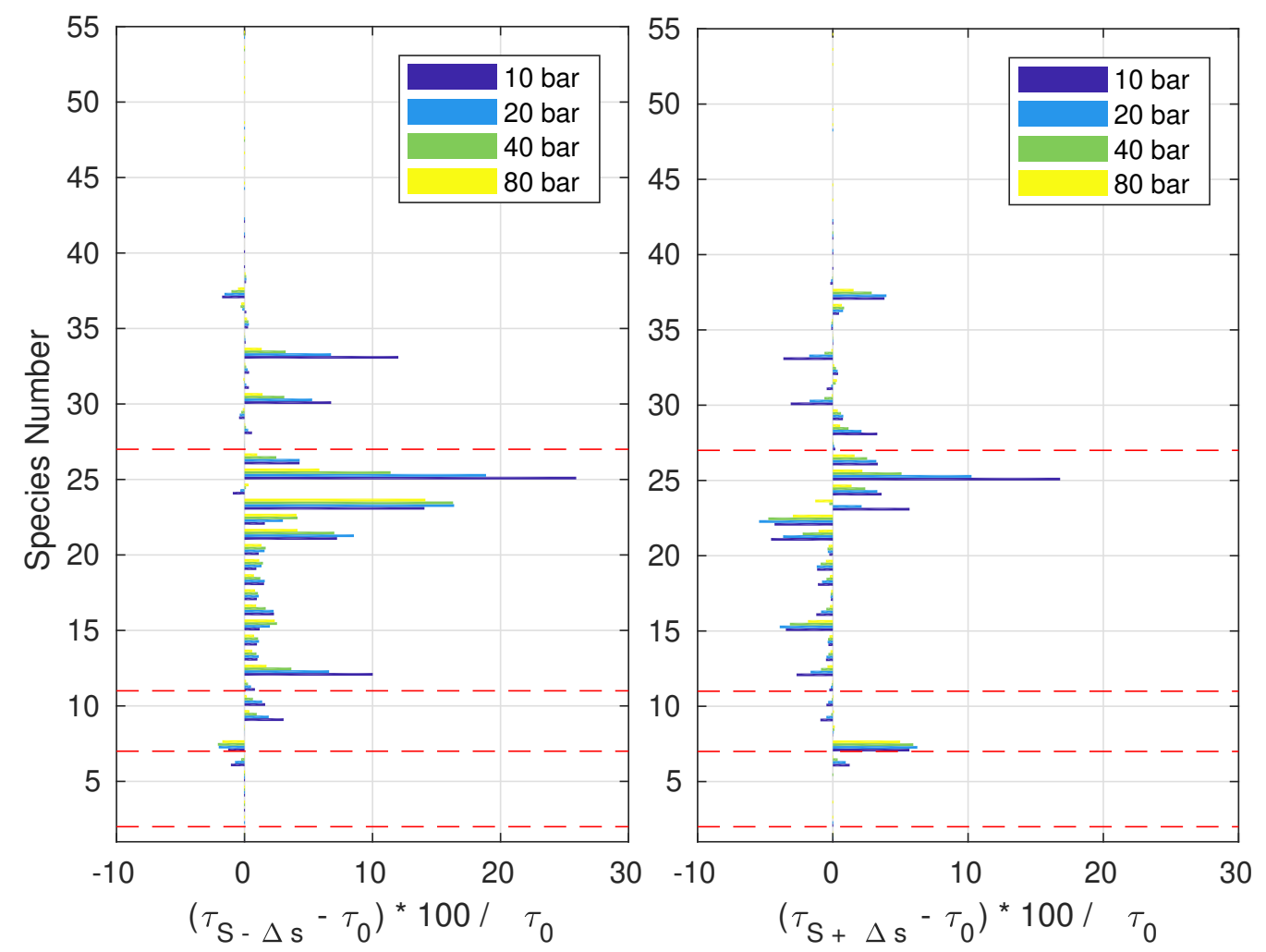

Figure 2: Variation of the ignition delay time with species entropies. The results are shown for a stoichiometric mixture $(\phi=1)$ at $\mathrm{T}_{0}=800 \mathrm{~K}$ and $\mathrm{p}_{0}=\{10,20,40,80\}$ bar. The left figure shows the variation of $\tau_{i g n}$ due to a negative perturbation in the entropy. The right figure shows the variation of $\tau_{i g n}$ due to a positive perturbation in the entropy.

As can be seen from Fig. 1, the major variations in ignition delay time are primarily due to the perturbations in the enthalpies of six species: $\mathrm{C}_{4} \mathrm{H}_{7} \mathrm{OH}-$ $1 \mathrm{OOH}-3 \mathrm{O}_{2}$ (species 12 ), $\mathrm{C}_{4} \mathrm{H}_{8} \mathrm{OH}-1 \mathrm{O}_{2}$ (species 23), $\mathrm{C}_{4} \mathrm{H}_{8} \mathrm{OH}-3 \mathrm{O}_{2}$ (species 25), $\mathrm{C}_{4} \mathrm{H}_{8} \mathrm{OH}-4 \mathrm{O}_{2}$ (species 26), $\mathrm{C}_{4} \mathrm{H}_{7} \mathrm{OH}-1 \mathrm{OOH}-3$ (species 28), and $\mathrm{C}_{4} \mathrm{H}_{7} \mathrm{OH}-$ $3 \mathrm{OOH}-1$ (species 33). Species 12, 23, 25 and 26 belong to thermodynamic class 4 , peroxy radicals, while species 28 and 33 belong to the hydroperoxide radicals, thermodynamic class 5 . This is a first indication of the impact of the thermodynamic classes affecting the variability in $\tau_{i g n}$. Also note that, these large-amplitude positive and negative perturbations in the enthalpies result in same-sign variations in $\tau_{i g n}$. This points to a non-monotonic behavior of $\tau_{i g n}$ with enthalpy variation, as further discussed below. The aforementioned species are important in the low and intermediate temperature ranges of the ignition of n-butanol because they control the extent low temperature radical chain branching pathways. Perturbing the enthalpies of peroxy radicals and hydroperoxide radicals alters the thermodynamic equilibrium between 
chain terminating and chain branching reaction pathways, and hence have a significant impact on ignition delay time.

The six species identified from Fig. 1 are still prevalent when entropy is perturbed. However, Fig. 2 shows that perturbations in the entropies do not result in as pronounced variations in $\tau_{i g n}$ as perturbations in enthalpies.

Similar variations in $\tau_{i g n}$ are observed when the initial pressure is increased for both enthalpy and entropy perturbations. Hence, at initial all pressures considered, the same six species identified are prominent.

\subsection{Sensitivity Analysis of Six Dominant Species}

Following the results of section 3.1 we focus our attention on the six dominant species where the highest percent variations in ignition delay time are observed. The same initial conditions for n-butanol combustion are investigated.

We are particularly interested in studying the variations of $\tau_{i g n}$ over the respective uncertainty range of the six major species due to perturbations in both their enthalpies and entropies. Again, we follow the same approach, detailed in section 2.4 , to calculate our primary quantity of interest, $\tau_{i g n}$. We discretize the range for enthalpy, $\left[\mathrm{H}_{f}-\Delta \mathrm{h}, \mathrm{H}_{f}+\Delta \mathrm{h}\right]$, and entropy, $[\mathrm{S}-\Delta \mathrm{s}$ $, \mathrm{S}+\Delta \mathrm{s}]$, using a canonical random variable, $\xi$, that breaks the interval into eleven evenly spaced discretization points. Figs. 3 and 4 represent the variations of $\tau_{i g n}$ with uncertain species enthalpies at the various discretization points at $\mathrm{p}_{0}=20$ bar and $\mathrm{p}_{0}=80$ bar, respectively, for all initial temperatures considered. Similarly, Fig. 5 shows the variations of $\tau_{i g n}$ with uncertain species entropies at $\mathrm{p}_{0}=80$ bar.

Fig. 3 shows that the variations of $\tau_{i g n}$ are notable and significant for the six species at the low and intermediate temperatures, 700 to $900 \mathrm{~K}$. At $1000 \mathrm{~K}$, the variability of $\tau_{i g n}$ is less pronounced. As the pressure increases, we see in Fig. 4 that the effect of uncertainties in the enthalpy on the variations of $\tau_{\text {ign }}$ are less prominent at 900 and $1000 \mathrm{~K}$, but still important at 700 and $800 \mathrm{~K}$ for all six species.

It is interesting to note that, as anticipated based on the results of the brute-force analysis presented earlier, that the ignition delay time may exhibit a non-monotonic behavior as individual species enthalpies are varied. Specifically, in some case $\tau_{i g n}$ is observed to admit a minimum in the range considered, whose location may depend on temperature and pressure. This behavior is due to the fact that changes in the thermodynamic properties of a single species affect both the energetics (i.e. heat release rates) and more importantly the kinetics of multiple reactions, namely by changing the affected equilibrium constants and consequently the corresponding reverse reaction 
rates. This may trigger competing effects, which are at the origin of the complex behavior observed in the results.
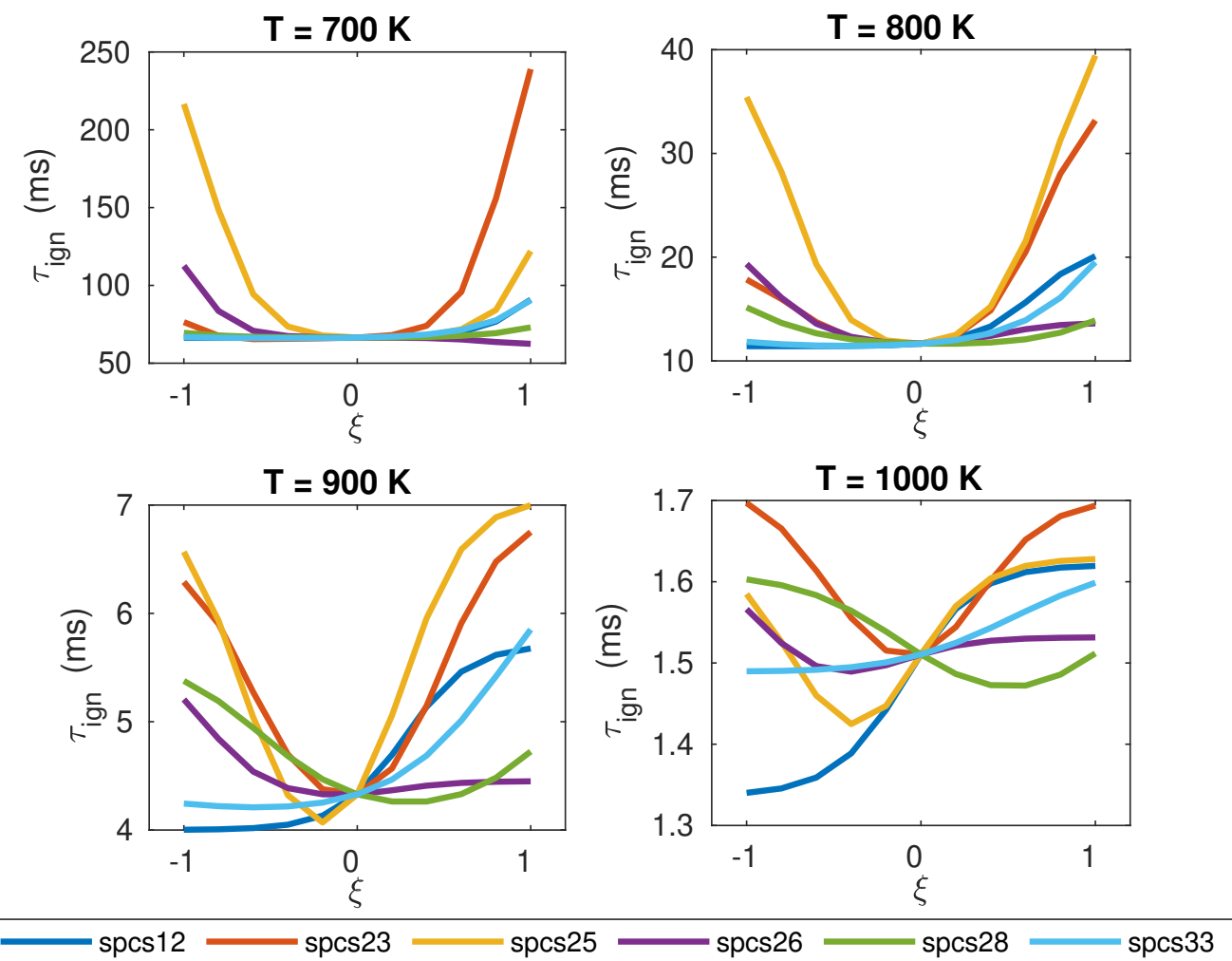

Figure 3: Variation of the ignition delay time with species enthalpies. The image of the canonical variable, $\xi$, shown on the $x$ axis is the individual range $\left[\mathrm{H}_{f}-\Delta \mathrm{h}, \mathrm{H}_{f}+\Delta \mathrm{h}\right]$ for each of the six species of interest. The results are shown for a stoichiometric mixture $(\phi=1)$ of $\mathrm{n}$-butanol combustion in air at $\mathrm{p}_{0}=20$ bar and $\mathrm{T}_{0}=\{700,800,900,1000\} \mathrm{K}$. 

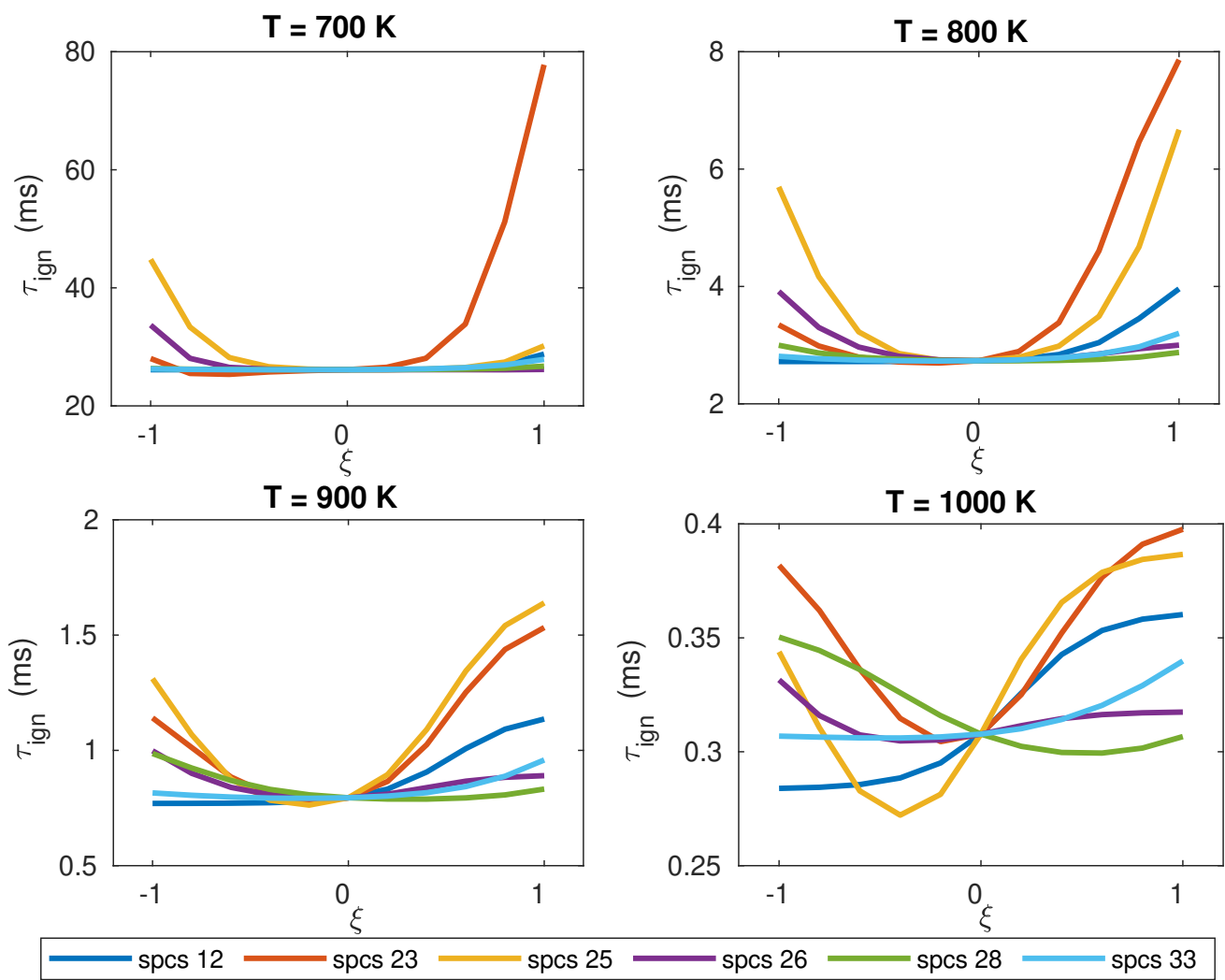

Figure 4: Variation of the ignition delay time with species enthalpies. The image of the canonical variable, $\xi$, shown on the $x$ axis is the individual range $\left[\mathrm{H}_{f}-\Delta \mathrm{h}, \mathrm{H}_{f}+\Delta \mathrm{h}\right]$ for each of the six species of interest. The results are shown for a stoichiometric mixture $(\phi=1)$ of n-butanol combustion in air at $\mathrm{p}_{0}=80$ bar and $\mathrm{T}_{0}=\{700,800,900,1000\} \mathrm{K}$.

As can be seen from Fig. 5, the variations of $\tau_{i g n}$ due to perturbations in entropy are not very pronounced when compared with perturbations in enthalpy. A close to flat variation is observed for almost all of the species with the exception of species $23\left(\mathrm{C}_{4} \mathrm{H}_{8} \mathrm{OH}-1 \mathrm{O}_{2}\right)$ and $25\left(\mathrm{C}_{4} \mathrm{H}_{8} \mathrm{OH}-3 \mathrm{O}_{2}\right)$ that exhibit noticeable variations in $\tau_{i g n}$ due to entropy perturbations at $\mathrm{T}_{0}=$ 700 and $800 \mathrm{~K}$. 

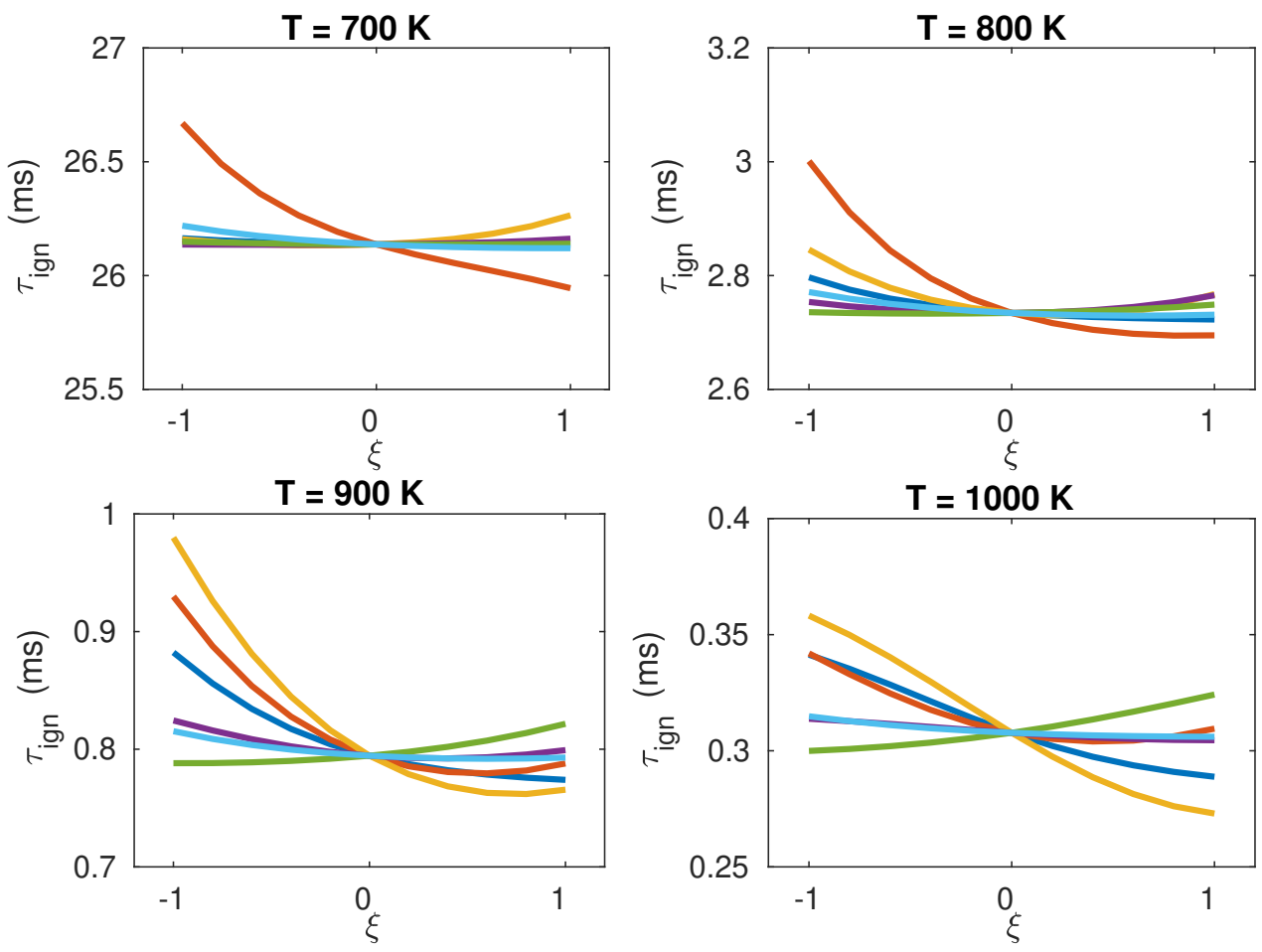

spcs $12=\operatorname{spcs} 23=\operatorname{spcs} 25$

spcs 26

spcs 33

Figure 5: Variation of the ignition delay time with species entropies. The image of the canonical variable shown on the $x$ axis is the individual range $[S-\Delta \mathrm{S}, \mathrm{S}+\Delta \mathrm{s}]$ for each of the six species of interest. The results are shown for a stoichiometric mixture $(\phi=1)$ of n-butanol combustion in air at $\mathrm{p}_{0}=80$ bar and $\mathrm{T}_{0}=\{700,800,900,1000\} \mathrm{K}$.

Another quantity that provides further insights into the variation of the ignition delay time is $|\Delta \tau|_{\max } / \tau_{0}$ where $|\Delta \tau|_{\max }=\left|\tau-\tau_{0}\right|_{\max }$ on the enthalpy range $\left[\mathrm{H}_{f}-\Delta \mathrm{h}, \mathrm{H}_{f}+\Delta \mathrm{h}\right]$. This ratio of the maximum of the difference between $\tau$ and $\tau_{0}$ in absolute value to the nominal $\tau_{0}$ characterizes peak variations of $\tau_{i g n}$. Since the trend of the variation of $\tau_{i g n}$ depicted in Figs 3, 4 and 5 is nonmonotonic, we choose to look at the peak variations of $\tau_{i g n}$.

For $\mathrm{p}_{0}=20$ bar we observe in Fig. 6 that at intermediate temperatures, the peak values are for $\mathrm{C}_{4} \mathrm{H}_{8} \mathrm{OH}-1 \mathrm{O}_{2}$ (species 23) at $700 \mathrm{~K}$ and $\mathrm{C}_{4} \mathrm{H}_{8} \mathrm{OH}-3 \mathrm{O}_{2}$ (species 25) at 800 and $900 \mathrm{~K}$, while at $1000 \mathrm{~K} \mathrm{C}_{4} \mathrm{H}_{7} \mathrm{OH}-1 \mathrm{OOH}-3 \mathrm{O}_{2}$ (species 12) shows the highest value. For $\mathrm{p}_{0}=80$ bar $\mathrm{C}_{4} \mathrm{H}_{8} \mathrm{OH}-1 \mathrm{O}_{2}$ (species 23) has the highest values at 700 and $800 \mathrm{~K}$ and $\mathrm{C}_{4} \mathrm{H}_{8} \mathrm{OH}-3 \mathrm{O}_{2}$ (species 25) at 900 and $1000 \mathrm{~K}$. At low to intermediate initial temperatures for both pressure conditions, we note that $|\Delta \tau|_{\max } / \tau_{0}>1$, reflecting the large impact of the uncertainty in the species enthalpies on the variability of $\tau_{i g n}$. At $1000 \mathrm{~K}$, we observe a significant drop in $|\Delta \tau|_{\max } / \tau_{0}$ with increasing $\mathrm{T}_{0}$ but as the pressure 
increases, the impact of $\mathrm{C}_{4} \mathrm{H}_{8} \mathrm{OH}-3 \mathrm{O}_{2}$ (species 25) becomes notable. Thus, the initial pressure can have significant impact on the peak variability of $\tau_{i g n}$.

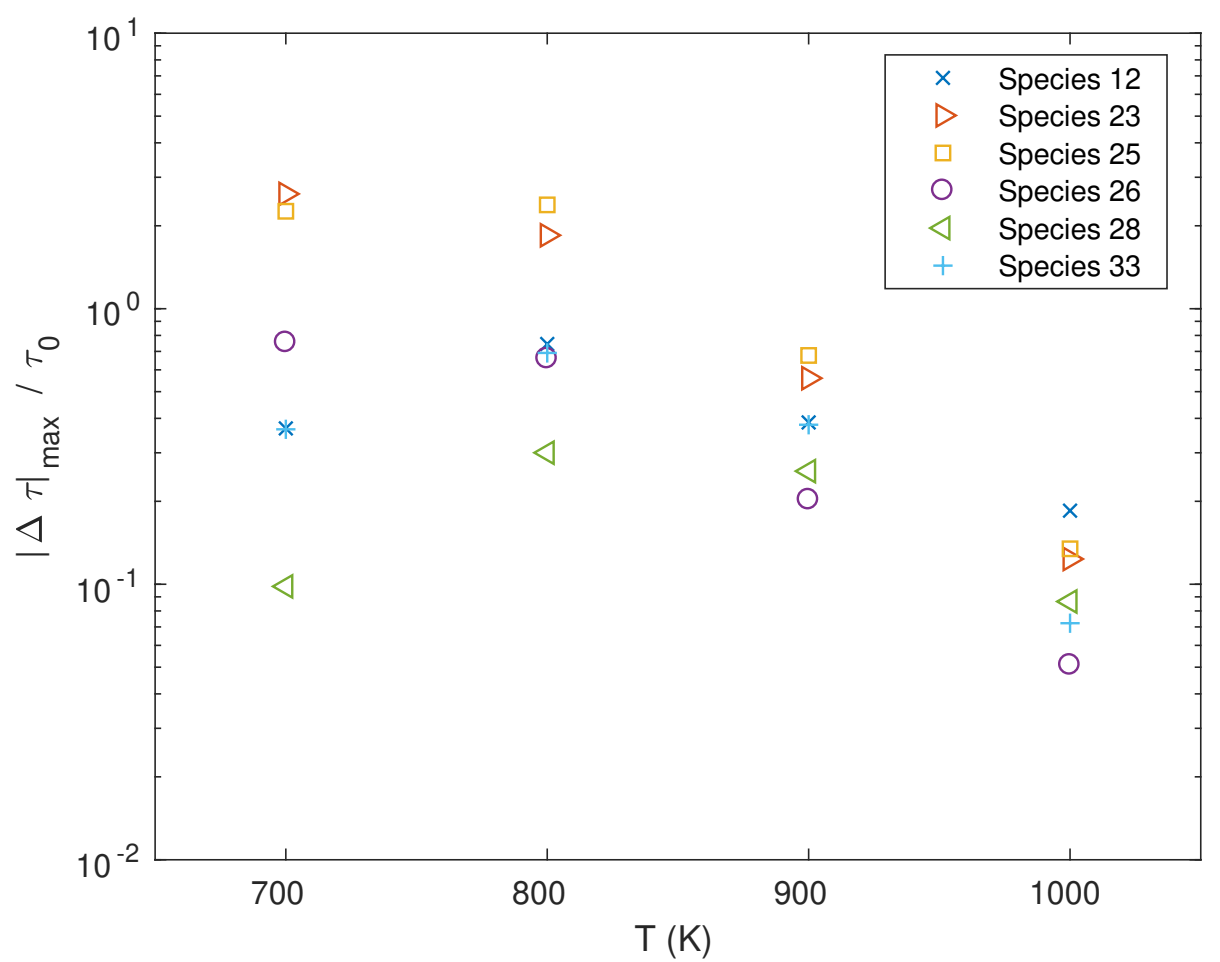

Figure 6: $|\Delta \tau|_{\max } / \tau_{0}$, for each of the six species of interest. Results are obtained using $\phi=1$ and $\mathrm{p}_{0}=20$ bar. 


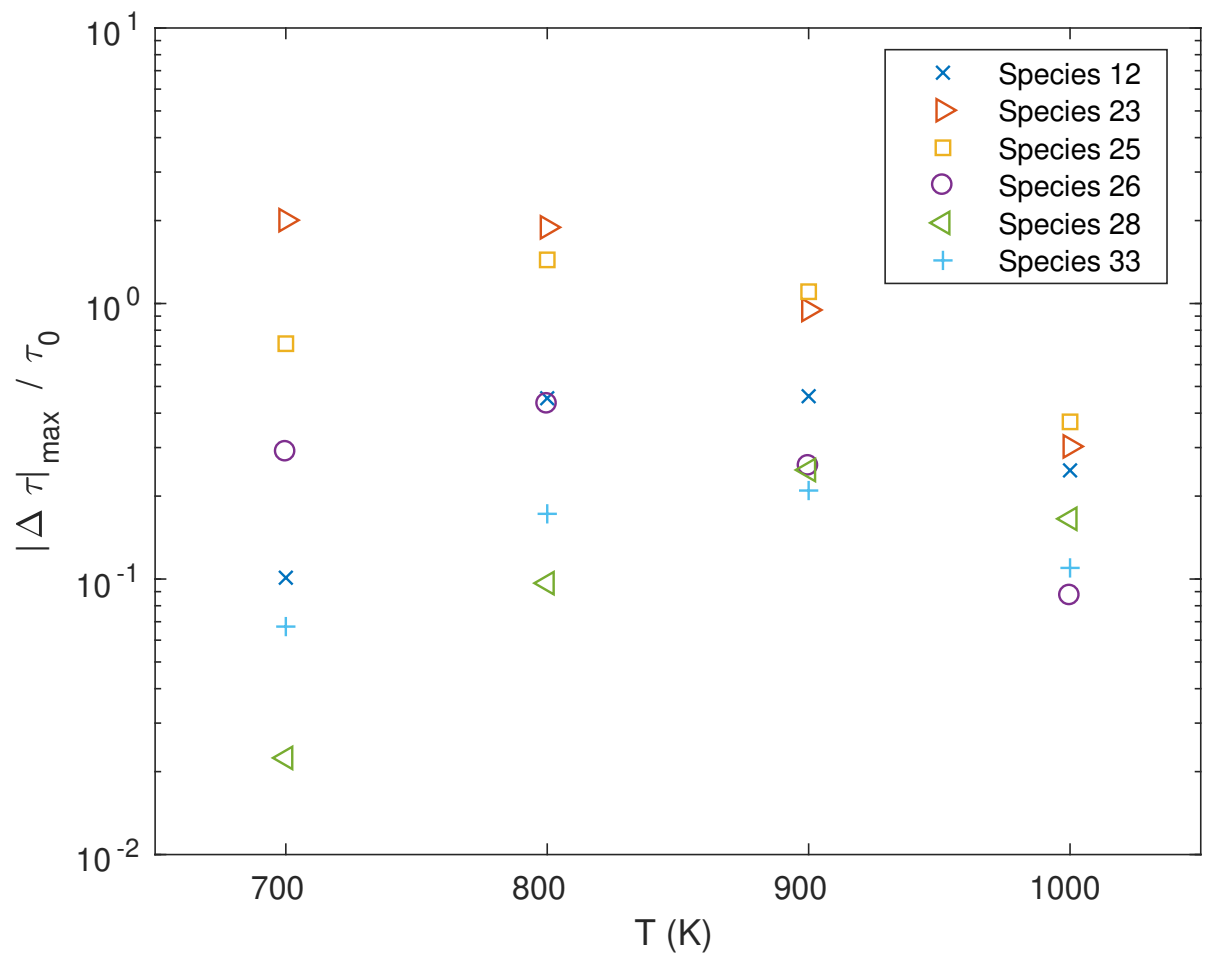

Figure 7: $|\Delta \tau|_{\max } / \tau_{0}$, for each of the six species of interest. Results are obtained using $\phi=1$ and $\mathrm{p}_{0}=80$ bar.

\section{Sensitivity Analysis of Thermodynamics Classes}

A global sensitivity analysis is conducted to understand the variability of the ignition delay time due to uncertainty in the enthalpies and entropies of the thermodynamics classes, introduced in section 2.2. The simulation conditions are the same as those reported in section 3.1, where the combustion of n-butanol in air occurs at stochiometry $(\phi=1)$ with a range of initial temperatures, $\mathrm{T}_{0}=\{700,800,900,1000\}(\mathrm{K})$, and pressures, $\mathrm{p}_{0}=\{10,20$, $40,80\}$ (bar). We begin by examining the suitability of the PC surrogate models of $\tau_{i g n}$. These surrogates are thereafter exploited in a variance-based global sensitivity analysis. Based on the results of the total sensitivity analysis we reduce our stochastic space to two dominant thermodynamics classes governing the variability in $\tau_{i g n}$ with uncertainties in both the enthalpies and entropies of these classes.

\subsection{Surrogates and Their Validity}

As previously introduced in section 2.2, the five thermodynamics classes include the fuel, alkoxy radicals, hydroxy alkyl radicals, peroxy radicals and 
alkylhydroxy hydroperoxide radicals. To each class, we associate uncertainties in both the enthalpies and entropies. Hence, ten uncertain groups of thermodynamic properties are obtained. The uncertainties of the individual thermodynamic classes are assumed independent as well as the uncertainties of the individual thermodynamic groups due to independent enthalpy and entropy uncertainties.

These uncertain thermodynamic groups are parametrized in terms of a 10-dimensional canonical random vector,

$$
\boldsymbol{\xi}=\left[\begin{array}{llllllllll}
\xi_{1}^{H_{f}} & \ldots & \xi_{i}^{H_{f}} & \ldots & \xi_{5}^{H_{f}} & \xi_{1}^{S} & \ldots & \xi_{i}^{S} & \ldots & \xi_{5}^{S}
\end{array}\right]
$$

where $\xi_{i}^{H_{f}}$ and $\xi_{i}^{S}$ are independent and identically distributed over $[-1,1]$. Thus, we shall refer to $\xi_{1}, \ldots, \xi_{5}$ as groups $1-5$. These are the random variables that parametrize the correlated uncertain enthalpies of species falling in classes 1-5, respectively. Similarly, groups 6-10 will be associated with $\xi_{6}, \ldots, \xi_{10}$, i.e. the canonical rv's that parametrize the entropies of species falling in classes $1-5$, respectively.

The adaptive pseudo-spectral projection technique described in section 2.5 is used to build the functional representations of $\tau_{i g n}(\boldsymbol{\xi})$.

Fig. 8 shows the probability density function of $\tau_{\text {ign }}$ at $\mathrm{p}_{0}=10$ bar and for two initial temperatures, $\mathrm{T}_{0}=800$ and $1000 \mathrm{~K}$. The distribution of $\tau_{i g n}$ at $\mathrm{T}_{0}=800 \mathrm{~K}$ is skewed to the right and exhibits a long right tail. The mean is also located to the right of the mode. On the other hand, a left-skewed distribution is observed at $\mathrm{T}_{0}=1000 \mathrm{~K}$ with the mean situated to the left of the mode. These distributions highlight the complexity of the representations of $\tau_{i g n}$ and the necessity to ensure that the computed PC surrogates provide suitable representations of $\tau_{i g n}$. 

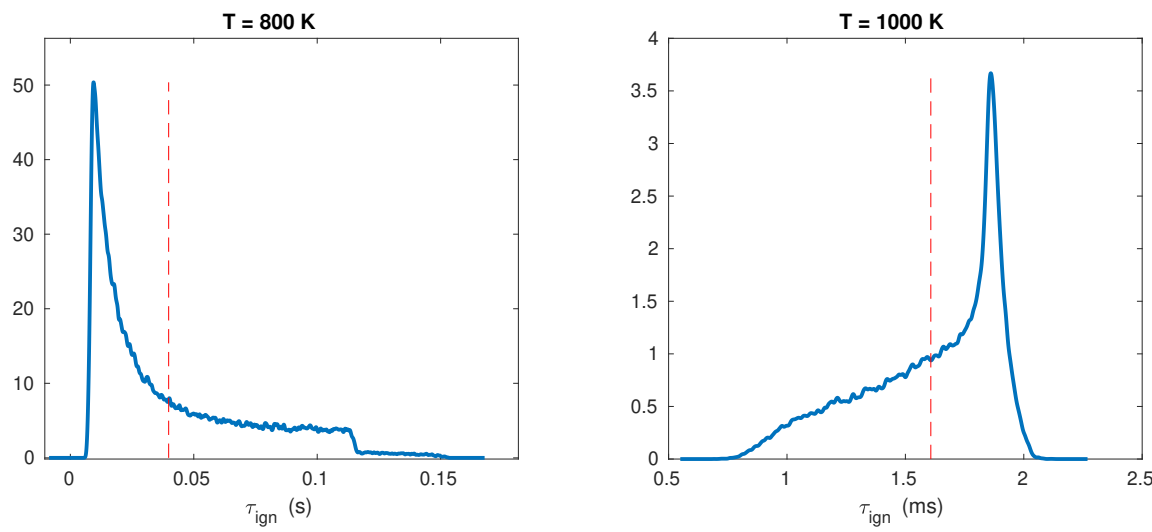

Figure 8: Distributions of $\tau_{i g n}$. Plotted results are obtained with $\mathrm{T}_{0}=800 \mathrm{~K}$ (left) and $\mathrm{T}_{0}=1000 \mathrm{~K}$ (right). In both cases, the initial pressure $\mathrm{p}_{0}=10$ bar and the equivalence ratio $\phi=1.0$. The distributions are obtained through kernel density estimation, based on random samples of $\tau_{i g n}$ generated from its PC representation. The dashed red lines reflect the locations of the means, $\mu$, which are at $0.0399 \mathrm{~s}$ and $1.607 \mathrm{~ms}$ for $800 \mathrm{~K}$ and $1000 \mathrm{~K}$, respectively. The coefficients of variation are 0.8176 and 0.1792 for $800 \mathrm{~K}$ and $1000 \mathrm{~K}$, respectively.

The ratios of the partial variances, associated with each polynomial order, to the total variance are presented at $\mathrm{T}_{0}=800$ and $1000 \mathrm{~K}$ and $\mathrm{p}_{0}=20 \mathrm{bar}$ in Figs 9 and 10, respectively. Both figures show that polynomials of order less than 6 contribute substantially to the variance of $\tau_{i g n}$. In contrast, higher order terms have insignificant contribution to the variance. These higher order terms appear because of the conservative tolerance specified for the aPSP technique. The insets showing the cumulative sum of the ratios of the partial variances over the total variance support this claim. In particular, the results indicate that for polynomial orders 6 or larger, the partial variance exceeds $99 \%$ of the total. This implies that for PC orders of 6 or larger the representation captures the variability of the QoI and thus provides a suitable surrogate. 


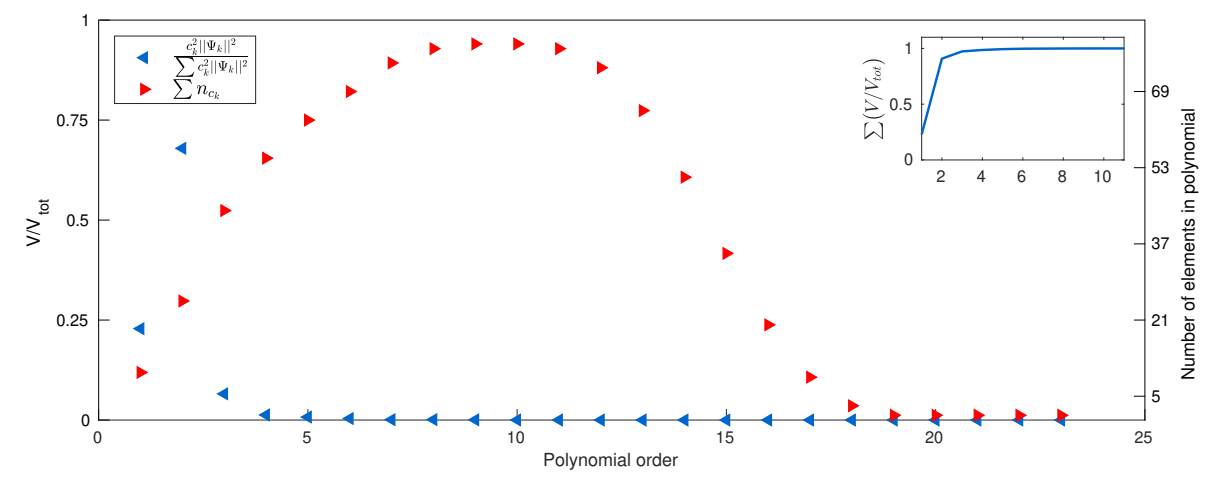

Figure 9: $V / V_{\text {tot }}(\triangleleft$; left vertical axis) and number of polynomials of order $p$ ( $\triangleright$; right vertical axis) versus the polynomial order. The results are generated using the surrogate obtained with $\mathrm{T}_{0}=800 \mathrm{~K}, \mathrm{p}_{0}=20 \mathrm{bar}$, and $\phi=1.0$. The inset shows the cumulative sum of the ratios of the partial variances over the total variance, which plateaus at 1 .

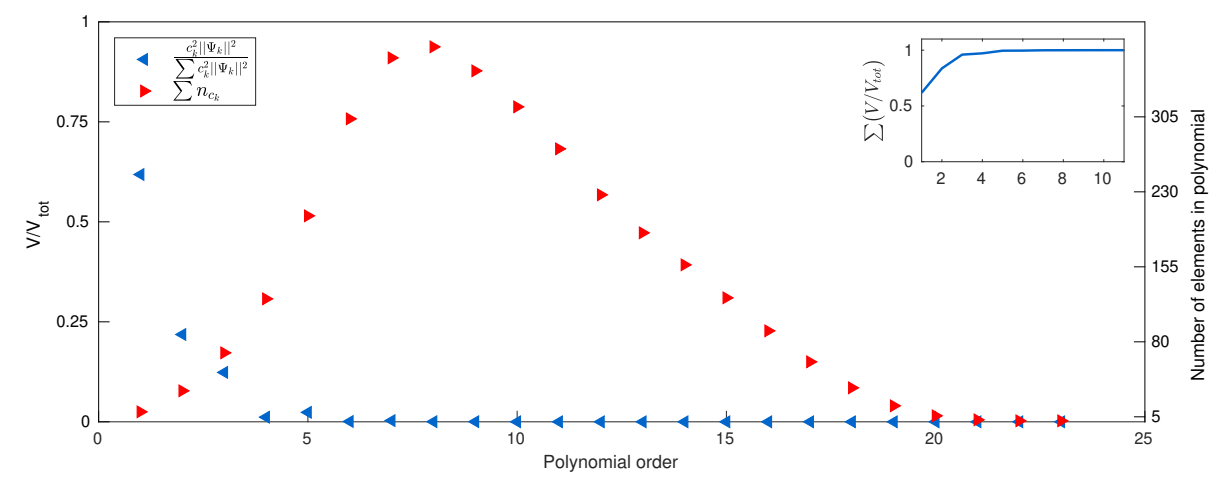

Figure 10: $V / V_{\text {tot }}(\triangleleft$; left vertical axis) and number of polynomials of order $p$ ( $\triangleright$; right vertical axis) versus the polynomial order. The results are generated using the surrogate obtained with $\mathrm{T}_{0}=1000 \mathrm{~K}, \mathrm{p}_{0}=20 \mathrm{bar}$, and $\phi=1.0$. The inset shows the cumulative sum of the ratios of the partial variances over the total variance, which plateaus at 1.

In order to shed light on the complexity of the response of $\tau_{\text {ign }}$ to uncertainties in the thermodynamic properties, Fig. 11 shows the values of $\tau_{i g n}$ versus $\xi_{4}$ for various instances of $\xi_{5}$ at $\mathrm{T}_{0}=800$ and $1000 \mathrm{~K}$ and $\mathrm{p}_{0}=20 \mathrm{bar}$. The figure clearly depicts how $\tau_{i g n}$ varies substantially in the negative range of $\xi_{4}$. At $\mathrm{T}_{0}=800 \mathrm{~K}$, when $\xi_{4}=-1$ and $-0.9062<\xi_{5}<0.9062, \tau_{\text {ign }}$ varies by an order of magnitude. When $\xi_{4}=0$, meaning the nominal values of the species in group 4 are used, the impact of the variability in $\xi_{5}$ on $\tau_{i g n}$ is much less pronounced. The variations of $\tau_{i g n}$ with $\xi_{5}$ almost completely subside in the positive range of $\xi_{4}$, with the curves collapsing to the same value at $\xi_{4}=1$. 

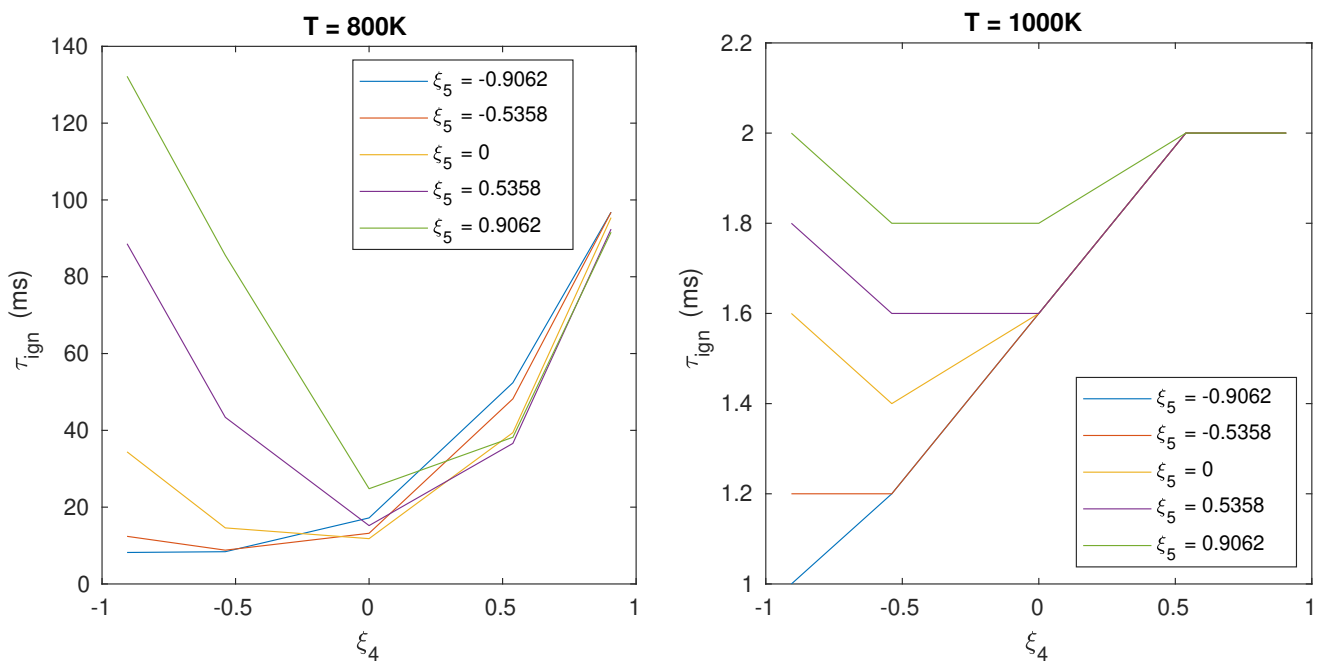

Figure 11: Ignition delay time versus $\xi_{4}$. Curves are generated for different values of $\xi_{5}$, as indicated. Results are obtained for $\mathrm{p}_{0}=20 \mathrm{bar}$ and $\mathrm{T}_{0}=800 \mathrm{~K}$ (left) and $1000 \mathrm{~K}$ (right).

Similar variations are observed at higher temperature, $\mathrm{T}_{0}=1000 \mathrm{~K}$, where the amplitude of the variations in $\tau_{i g n}$ doubles in the negative range of $\xi_{4}\left(\xi_{4}=-1\right)$ for the various values of $\xi_{5}\left(-0.9062<\xi_{5}<0.9062\right)$.

Lastly, we examine the quality of the representation by generating qq plots contrasting the representation to underlying data. We also compare the performance of aPSP and LASSO at $\mathrm{T}_{0}=1000 \mathrm{~K}$ and $\mathrm{p}_{0}=20$ bar. Results in Fig. 12 show a good agreement between the surrogate representations, from both aPSP and LASSO, and the simulation predictions of $\tau_{i g n}$ where a straight line $(x=y)$ is observed. This is a clear indication of the validity of the surrogate representations of $\tau_{i g n}$ from aPSP and LASSO. We also note that, as can be seen from Fig. 12, the aPSP points lie closer to the diagonal than the LASSO points. aPSP thus outperforms LASSO, though both representations evidently provide faithful surrogates of the QoI. 


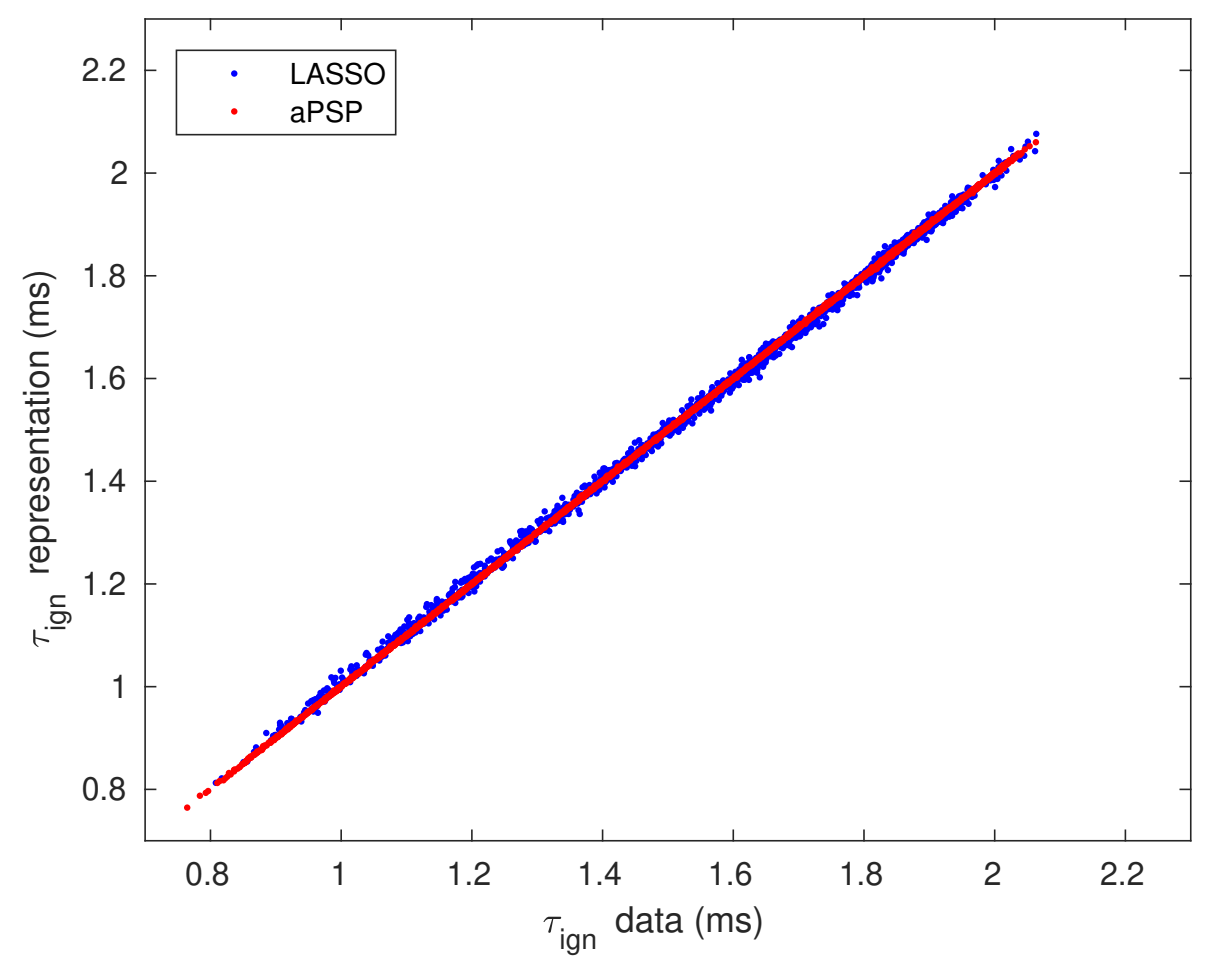

Figure 12: Surrogate (aPSP and LASSO) representation of $\tau_{i g n}$ versus underlying simulation results. The results are obtained using $\mathrm{T}_{0}=1000 \mathrm{~K}$, pressure $\mathrm{p}_{0}=20 \mathrm{bar}$, and $\phi$ $=1.0$. The means are 1.607 and $1.609 \mathrm{~ms}$ and the coefficients of variation are 0.179 and 0.2865 for the aPSP and LASSO representations respectively.

\subsection{Global Sensitivity Analysis of Thermodynamic Classes}

After assessing the validity of our surrogate models, we exploit the orthoginality of the basis in order to perform a global sensitivity analysis (GSA). A variance decomposition approach is applied to infer the contribution of each uncertain parameter on the variability of $\tau_{i g n}$. The first and total order sensitivities are obtained from GSA where the first order sensitivity indices show the direct contribution of the individual or group of parameters while the total sensitivity indices, $\mathbb{T}_{i}$, where $i \in[1-10]$, account additionally for the mixed interactions among the uncertain parameters.

Fig. 13 shows the total sensitivity indices of $\tau_{i g n}$ with respect to the ten thermodynamic groups. As previously introduced, groups 1 to 5 represent the uncertainties in the enthalpies of the corresponding five thermodynamic classes while groups 6 to 10 represent the uncertainties in the entropies of these classes. At all initial temperature and pressure conditions, the largest sensitivity indices are notably those corresponding to uncertainty in group 
4 , the uncertainty in the enthalpies of class 4 (peroxy radicals). At the lower bound of the intermediate temperature range, $700 \mathrm{~K}$, there is an interplay between groups 4 and 5, uncertainties in enthalpies of class 4 (peroxy radicals) and class 5 (hydroperoxide radicals). As the temperature and pressure increase, $\mathbb{T}_{5}$ and $\mathbb{T}_{10}$ decrease monotonically. At the same time, $\mathbb{T}_{4}$ and $\mathbb{T}_{9}$ increase monotonically. The impact of all other groups on the variability of $\tau_{i g n}$ is negligible.
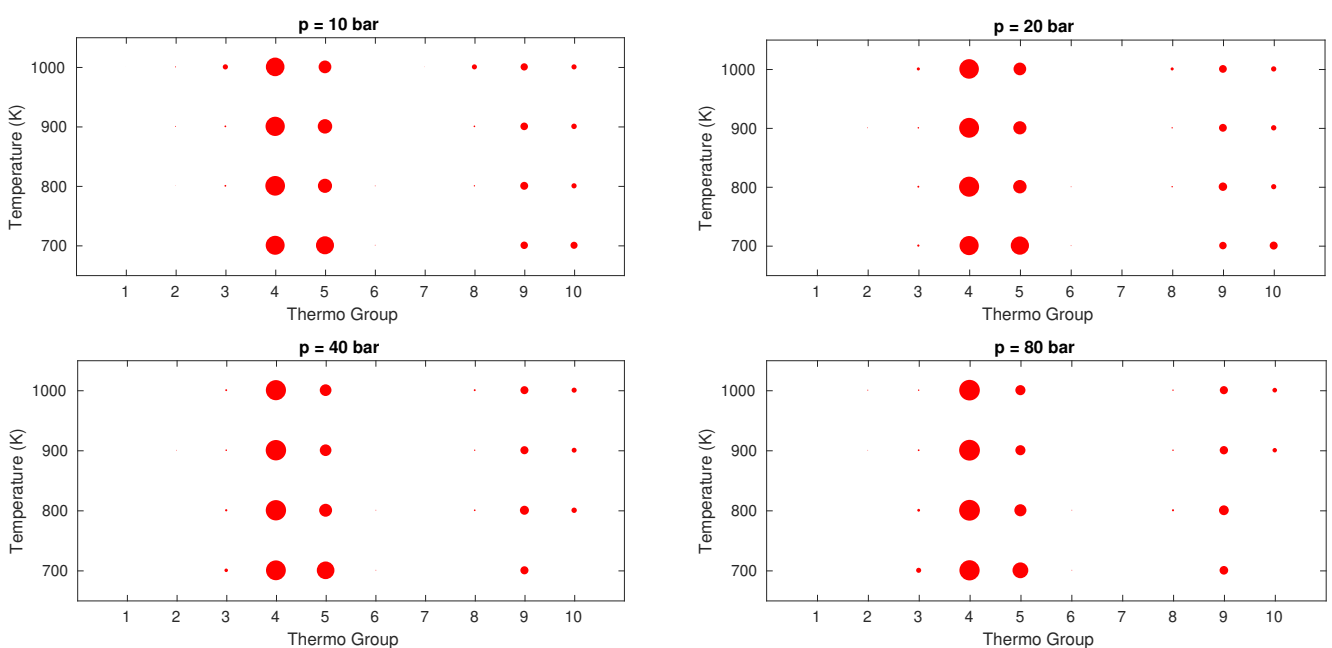

Figure 13: Total sensitivity indices of $\tau_{i g n}$ with respect to the 10 thermodynamic groups. Plotted are results obtained for a stoichiometric mixture $(\phi=1)$ at all initial temperatures considered. The subplots correspond to the four initial pressures, as indicated. The diameter of the circle is proportional to the sensitivity index for $\tau_{i g n}$. The largest circle reflects a sensitivity index of 0.8927 , occurring for group 4 at $\mathrm{T}_{0}=900 \mathrm{~K}$ and $\mathrm{p}_{0}=$ 80 bar. The smallest circles may not be clearly visible and sensitivity indices falling less than $1 \times 10^{-4}$ are removed.

We are also interested in looking at the coefficient of variation of $\tau_{i g n}$, calculated as the ratio of the standard deviation to the mean, $\mathrm{CoV} \equiv \sigma / \mu$. On the left plot of Fig. 14, the nominal $\tau_{i g n}$ versus $\mathrm{T}_{0}$ is presented for all $\mathrm{p}_{0}$, and the $\mathrm{CoV}$ is depicted on the right plot. The nominal $\tau_{i g n}$ is obtained from constant volume simulations of n-butanol combustion in air without perturbing any thermodynamics properties. As can be seen, $\tau_{i g n}$ monotonically decreases with increasing temperature. The same behavior of monotonic decrease is observed at fixed temperature and increasing pressure. The $\mathrm{CoV}$ is largest at low $\mathrm{T}_{0}$ and decreases with increasing pressure. However, when the temperature increases $\left(\mathrm{T}_{0} \geq 800 \mathrm{~K}\right)$, the trend is reversed and the $\mathrm{CoV}$ increases with increasing pressure. 

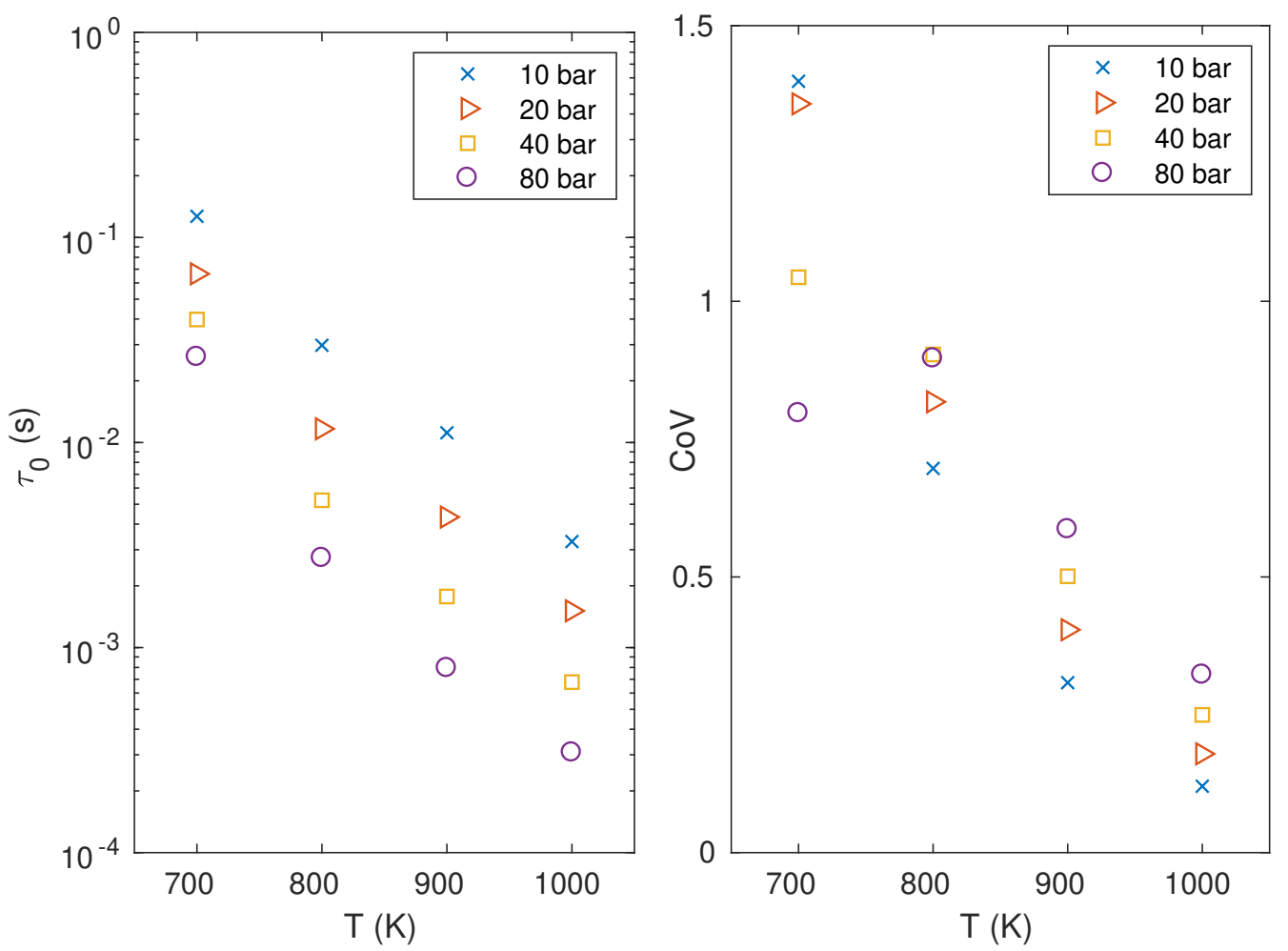

Figure 14: Ignition delay time at nominal conditions for a stoichiometric mixture $(\phi=1)$ of $n$-butanol combustion in air at $\mathrm{p}_{0}=\{10,20,40,80\}$ bar and $\mathrm{T}_{0}=\{700,800,900$, $1000\} \mathrm{K}$ (left plot). The coefficient of variation, $\mathrm{CoV} \equiv \sigma / \mu$, is plotted on the right.

\subsection{Sensitivity Based Reduction}

As was noted in section 4.2, uncertainties in the enthalpies and entropies of thermodynamic classes 4 and 5 are dominant and mostly influencing the variability in $\tau_{\text {ign }}$ over the entire range of temperatures and pressures. Therefore, we investigate the suitability of a 4 -d reduced model accounting only for uncertainties in the enthalpies and entropies of thermodynamic classes 4 and 5, while all other parameters are fixed to their nominal values.

Fig. 15 compares the total sensitivity indices of $\tau_{\text {ign }}$ for the full and reduced models for a stoichiometric mixture $(\phi=1)$ at the same initial temperature, $\mathrm{T}_{0}=800 \mathrm{~K}$, and all pressures, $\mathrm{p}_{0}=\{10,20,40,80\}$ bar. The differences between the total sensitivity indices of both models are evidently negligible. This provides more confidence in the viability of the reduction. 


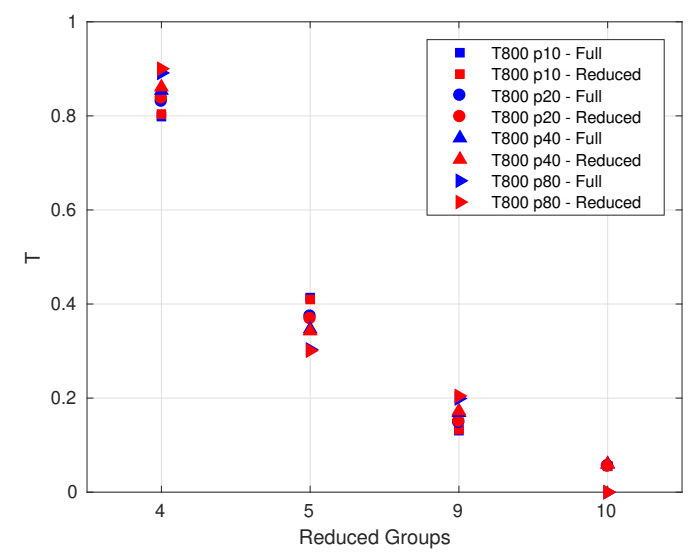

Figure 15: Total sensitivity indices of the ignition delay time for the full and reduced models for a stoichiometric mixture $(\phi=1)$ at different initial temperatures and pressures.

We proceed with the surrogate representations of the reduced model and examine the Sobol decomposition of the variance of $\tau_{i g n}$. Fig. 16 shows that at $\mathrm{T}_{0}=700 \mathrm{~K}$ and $\mathrm{p}_{0}=20$ bar mixed interactions between groups 1 and 2 have an important effect on the variability of $\tau_{i g n}$. This appears as a signature behaviour to what was previously observed in Fig. 11 where it was evident that the joint sensitivities of $\xi_{4}$ and $\xi_{5}$ play an important role specifically at low $\mathrm{T}$ where the range of variability of $\tau_{i g n}$ is high.

On the other hand, we observe in Fig. 17 that at $\mathrm{T}_{0}=900 \mathrm{~K}$ and $\mathrm{p}_{0}=$ 80 bar, the variability in $\tau_{\text {ign }}$ is mostly due to group 1, uncertainty in the enthalpies of thermodynamic class 4 . Hence the increase in initial temperature is coupled with a dominance of an uncertain group on the variability in $\tau_{i g n}$. When read in light of Fig. 11 similar conclusions can be drawn since we depicted a dramatically reduced range of variability in $\tau_{i g n}$ at the higher initial temperatures.

The end target of a sensitivity analysis is to highlight the dominant groups for the purpose of calibration. Hence, based on the previous conclusions from Figs. 16 and 17, when calibrating the thermodynamic properties at high initial temperatures, it is reasonable to focus on the enthalpies of peroxy radicals (thermodynamic class 4 ), parametrized by $\xi_{1}$, since they dominate the variability in $\tau_{i g n}$. However, at low initial temperatures, considering observational data of $\tau_{i g n}$ for the purpose of calibration should not overlook the strong joint sensitivity, $\xi_{\{1,2\}}$, of groups 1 and 2 for thermodynamic classes 4 and 5 . 


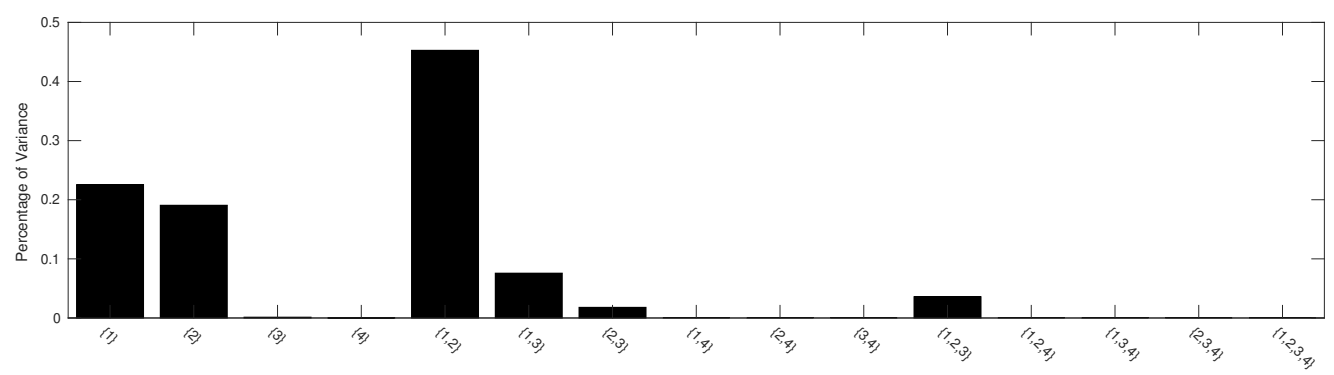

Figure 16: Sobol decomposition of the variance of $\tau_{i g n}$. The results are plotted for $\mathrm{T}_{0}=$ $700 \mathrm{~K}$ and $\mathrm{p}_{0}=20$ bar.

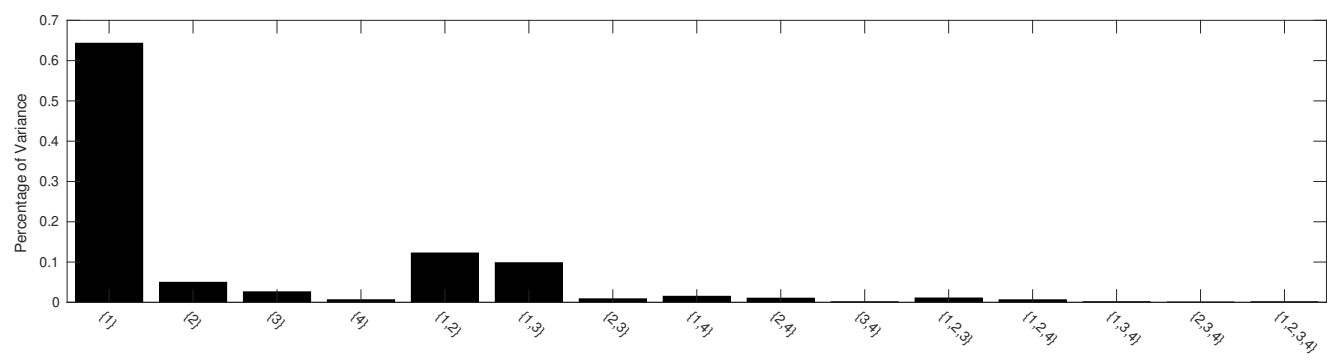

Figure 17: Sobol decomposition of the variance of $\tau_{i g n}$. The results are plotted for $\mathrm{T}_{0}=$ $900 \mathrm{~K}$ and $\mathrm{p}_{0}=80$ bar.

\section{Combined Kinetic Rates and Thermodynamics Classes}

Both analyses conducted in sections 3 and 4 demonstrate the importance of the uncertainty in thermodynamic properties on the variability of $\tau_{i g n}$. However, when compared to the impact of uncertain rate rules, does this uncertainty in thermodynamic properties have a pronounced effect on the ignition delay time? In this section, we explore this effect of the combined uncertainty in rate rules and thermodynamic properties on the variability in $\tau_{\text {ign }}$.

An eight-dimensional random space, $\boldsymbol{\xi}=\left[\begin{array}{lllll}\xi_{1} & \ldots & \xi_{i} & \ldots & \xi_{8}\end{array}\right]$, is considered. $\xi_{1}, \ldots, \xi_{4}$ parametrize the uncertainty in the four dominant reaction classes, namely reaction classes $2,11,15$ and 16 , respectively. $\xi_{5}$ and $\xi_{6}$ parametrize the uncertainty in the enthalpies of thermodynamic classes 4 and 5 , peroxy and hydroperoxide radicals, respectively, and $\xi_{7}$ and $\xi_{8}$ parametrize the uncertainty in the entropies of the two thermodynamic classes 4 and 5 . The uncertainty factors, UFs, of rate rules are adopted from [36] where to each reaction class a temperature-independent UF is assigned, and the uncertainty propagates to the pre-exponential constant, A, of the Arrhenius expression. 
A latin hypercube sample is used to generate random samples for $\boldsymbol{\xi}$ where the $\xi_{i}$ 's are independent and uniformly distributed over $[-1,1]$. LASSO is then utilized to build the functional representation of $\tau_{\text {ign }}(\boldsymbol{\xi})$. We limit our analysis to a range of initial temperatures, $\mathrm{T}_{0}=\{800,900,1000\}(\mathrm{K})$, and initial pressures, $\mathrm{p}_{0}=\{10,20,40,80\}$ (bar), at stoichiometric conditions.

Figs. 18 and 19 show the Sobol decomposition of the variance of $\tau_{i g n}$ at $\mathrm{T}_{0}=900 \mathrm{~K}$ and two different pressures $\mathrm{p}_{0}=10$ and 80 bar, respectively. We note the evident effect of pressure on the sensitivity of $\tau_{i g n}$. At low pressure, Fig. 18, reaction class 2, H-atom abstraction from the fuel, exhibits the highest percentage of variance of $\tau_{i g n}$. As the pressure increases, the effect of the uncertainty in the enthalpies of thermodynamics group 4 become more prominent alongside uncertainties in reaction class 2. Mixed interactions are more noticeable at lower temperatures $(800 \mathrm{~K})$ higher pressures $(80 \mathrm{bar})$ than at higher temperatures and lower pressures as can be seen in Table 2 and discussed below.

Based on the results presented in [36], it is observed that at intermediate temperature conditions, $\tau_{i g n}$ is mostly sensitive to uncertainties in reaction class 2 - H-atom abstraction from the fuel - and reaction class 15 - the ROO radical isomerization reactions $(\mathrm{ROO}=\mathrm{QOOH})$ along with the Waddington type reactions - and reaction class 16 - the concerted elimination of $\mathrm{HO}_{2}$ from ROO radical. However, reaction classes 15 and 16 do not apprear to have any noticeable impact on the variability of $\tau_{i g n}$, in the current study. Hence, we investigate the reactions constituting these two reaction classes in our mechanism file. Since all the reactions are reversible and no reverse rates are specified, the rate constants for the reverse reactions are calculated using the thermodynamics properties. Therefore, when these thermodynamics properties are fixed in [36], uncertainties in reaction classes 15 and 16 were important. Nevertheless, when we perturb the thermodynamics properties, we observe that the uncertainties in group 5 are dominant, rendering the calibration of the pre-exponential factor insignificant compared to the uncertainties in the thermodynamics properties. 


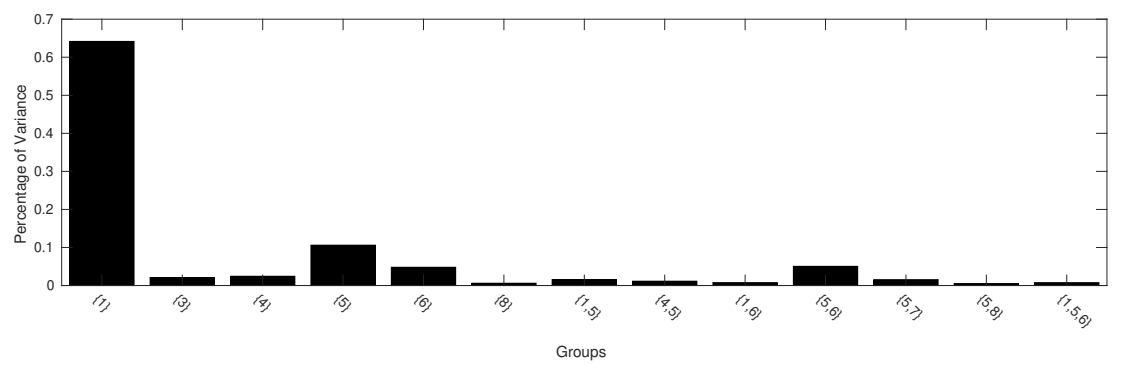

Figure 18: Sobol decomposition of the variance of $\tau_{i g n}$. The results are plotted at $\mathrm{p}_{0}=$ 10 bar and $T_{0}=900 \mathrm{~K}$. All sensitivities less than 0.005 are ignored.

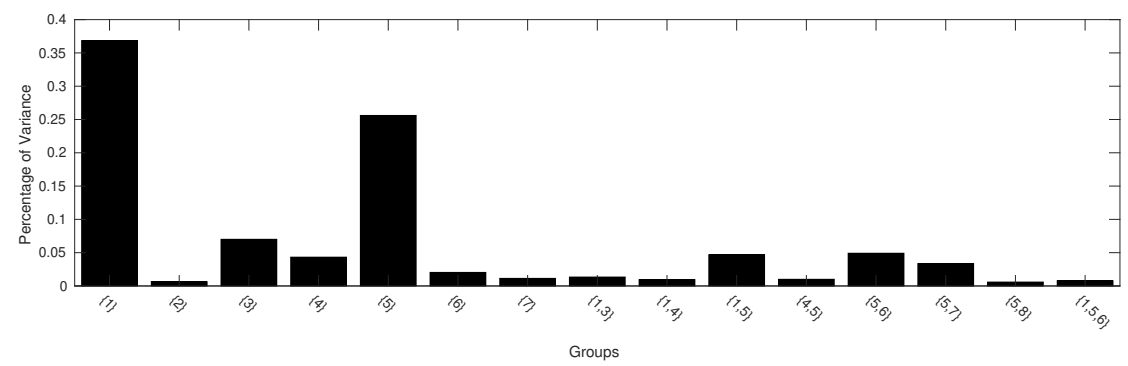

Figure 19: Sobol decomposition of the variance of $\tau_{i g n}$. The results are plotted at $\mathrm{p}_{0}=$ 80 bar and $T_{0}=900 \mathrm{~K}$. All sensitivities less than 0.005 are ignored.

Fig. 20 shows the total sensitivity indices of $\tau_{i g n}, \mathbb{T}_{i}, i=1, \ldots, 8$. $\xi_{1}$, parametrizing the uncertainty in reaction class 2, exhibits the highest values of $\mathbb{T}$. At intermediate temperatures, 800 and $900 \mathrm{~K}$, in addition to $\xi_{1}$, uncertainties in the enthalpies of thermodynamic class 4 (peroxy radicals), $\xi_{5}$, are important. To a lesser degree, $\xi_{6}$, parametrizing uncertainties in the entopies of thermodynamic class 4 , also appears and its effect decreases with increasing pressure. At high temperature $(1000 \mathrm{~K})$ and low pressure (10 bar), $\xi_{1}$ is dominant while at higher pressure ( 80 bar) $\xi_{1}$ and $\xi_{5}$ have significant sensitivity indices. The general trend in $\mathbb{T}$ shows that as the temperature increases, $\xi_{5}$ become less prevailing while $\xi_{1}$ becomes more dominant. On the contrary, as the pressure increases, $\xi_{1}$ shows a decreasing total sensitivity index, while, $\xi_{5}$ and, to a lesser extent, $\xi_{6}$ mark an increasing total sensitivity index. 

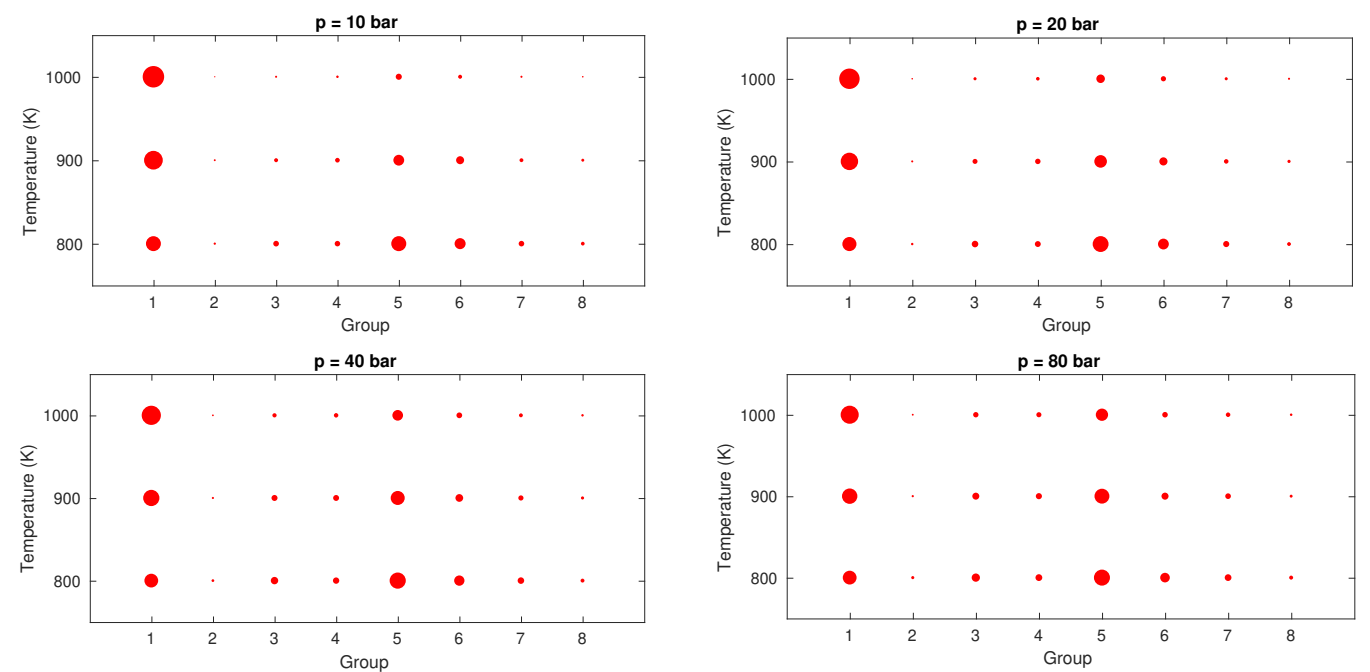

Figure 20: Total order sensitivity indices of ignition delay time at $\mathrm{p}_{0}=\{10,20,40,80\}$ bar and $\mathrm{T}_{0}=\{800,900,1000\} \mathrm{K}$. The maximum total sensitivity is 0.9041 at $\mathrm{p}_{0}=10$ bar and $\mathrm{T}_{0}=1000$ bar corresponding to reaction class 2 (H-atom abstraction from the fuel).

Table 2 presents the sensitivity indices of all reaction classes, $\mathbb{S}_{\{1-4\}}$, sensitivity indices of all thermodynamics groups, $\mathbb{S}_{\{5-8\}}$, and the joint sensitivity indices of the reaction classes and thermodynamics groups, $\mathbb{S}_{\{1-4\},\{5-8\}}$. Consistent with the results concluded from Fig. 20, we note that $\mathbb{S}_{\{1-4\}}$ decreases monotonically with increasing pressure at 900 and $1000 \mathrm{~K}$. On the other hand, at $800 \mathrm{KS}_{\{1-4\}}$ is not monotonic and exhibits a weak minimum. As the temperature increases, a monotonic increase in $\mathbb{S}_{\{1-4\}}$ is observed for all pressures. Additionally, in conjunction with Fig. 20, we note that $\mathbb{S}_{\{1-4\}}$ is dominated by $\mathbb{S}_{1}$, sensitivity index for reaction class 2 .

$\mathbb{S}_{\{5-8\}}$ increases monotonically at 900 and $1000 \mathrm{~K}$ with increasing pressure. Again, at $800 \mathrm{~K}$ the behavior is not monotonic with increasing pressure. A monotonic decrease is noted with increasing temperatures for all pressures.

Another important takeaway from Table 2 is that except at high temperatures and low pressures, thermodynamic uncertainties are important. At intermediate temperature $(800 \mathrm{~K})$, the sensitivity indices of $\tau_{i g n}, \mathbb{S}_{\{1-4\}}$ and $\mathbb{S}_{\{5-8\}}$, are of the same order, thus shedding light on the critical role of uncertain thermodynamic properties on accurately predicting the ignition delay time.

Finally, we note that $\mathbb{S}_{\{1-4\},\{5-8\}}$ increases monotonically as the pressure increases at all temperature conditions and decreases monotonically with increasing temperatures at all pressures. This second order sensitivity index, due to mixed interactions between reaction rates and thermodynamics properties, is relatively small, hence highlighting that the cross talk between 
kinetic and thermodynamic uncertainties is weak and that the effect of one reaction class, namely $\mathrm{H}$-atom abstraction from the fuel (reaction class 2) and of one thermodynamic group, the enthalpies of the peroxy radicals, dominate the sensitivity indices of $\tau_{\text {ign }}$ due to variability in groups $\{1-4\}$ and $\{5-8\}$, respectively, at the considered ranges of temperature and pressure.

\begin{tabular}{|l|l|c|c|c|}
\hline $\mathrm{T}(\mathrm{K})$ & $\mathrm{p}$ (bar) & $\mathbb{S}_{\{1-4\}}$ & $\mathbb{S}_{\{5-8\}}$ & $\mathbb{S}_{\{1-4\},\{5-8\}}$ \\
\hline 800 & 10 & 0.4393 & 0.4551 & 0.1056 \\
& 20 & 0.4036 & 0.4802 & 0.1162 \\
& 40 & 0.4018 & 0.4749 & 0.1233 \\
& 80 & 0.4252 & 0.4467 & 0.1281 \\
\hline 900 & 10 & 0.6980 & 0.2422 & 0.0598 \\
& 20 & 0.6166 & 0.3077 & 0.0758 \\
& 40 & 0.5535 & 0.3591 & 0.0873 \\
& 80 & 0.5151 & 0.3916 & 0.0933 \\
\hline 1000 & 10 & 0.9073 & 0.0744 & 0.0183 \\
& 20 & 0.8245 & 0.1389 & 0.0366 \\
& 40 & 0.7370 & 0.207 & 0.0560 \\
& 80 & 0.6655 & 0.2619 & 0.0725 \\
\hline
\end{tabular}

Table 2: Sensitivity indices of kinetic rates (4 classes), thermodynamics groups (4 groups) along with the joint sensitivity indices of the kinetic rates and thermodynamics groups. The sum of the entries in each of the rows is 1.0.

It is thus clear that uncertainties in thermodynamic and kinetic properties have similar impact at certain temperatures and pressures. Therefore, when conducting calibration studies, a large source of variation from thermodynamic properties cannot be ignored and must be addressed for more accurate and meaningful model predictions.

\section{Conclusions}

This work aimed at investigating the sensitivity of ignition delay time due to uncertainties in the thermodynamic properties, and the combined uncertainty in rate rules and thermodynamic classes. A constant volume combustion of n-butanol at stoichiometry $(\phi=1)$ is studied over a range of initial temperatures and pressures, using the detailed mechanism of Sarathy et al. [47].

A brute force analysis was first conducted and followed by a refined 1D analysis. Results showed that large variations in $\tau_{i g n}$ are mainly due to variability in the enthalpies of six species belonging to thermodynamic classes 4 and 5, namely: $\mathrm{C}_{4} \mathrm{H}_{7} \mathrm{OH}-1 \mathrm{OOH}-3 \mathrm{O}_{2}$ (species 12 ), $\mathrm{C}_{4} \mathrm{H}_{8} \mathrm{OH}-1 \mathrm{O}_{2}$ (species 
23), $\mathrm{C}_{4} \mathrm{H}_{8} \mathrm{OH}-3 \mathrm{O}_{2}$ (species 25 ), $\mathrm{C}_{4} \mathrm{H}_{8} \mathrm{OH}-4 \mathrm{O}_{2}$ (species 26), in thermodynamic class 4 , peroxy radicals, and $\mathrm{C}_{4} \mathrm{H}_{7} \mathrm{OH}-1 \mathrm{OOH}-3$ (species 28), and $\mathrm{C}_{4} \mathrm{H}_{7} \mathrm{OH}-$ $3 \mathrm{OOH}-1$ (species 33 ), in thermodynamic class 5 , hydroperoxide radicals. In addition, simulations showed that $\tau_{\text {ign }}$ exhibits a complex nonmonotonic behavior with species enthalpies. On the other hand, a close to flat variation was observed due to variability in the species' entropy, with the exception of species 22 and 23 for which a noticeable variations in $\tau_{i g n}$ at $\mathrm{T}_{0}=700$ and $800 \mathrm{~K}$. Hence, the variations in $\tau_{i g n}$ due to perturbations in species enthalpies are significant and more pronounced than variations due to perturbations in species entropies.

A forward UQ study for $\tau_{\text {ign }}$ was conducted with over a 10-d space of random variables parameterizing the uncertainty in the enthalpies and entropies of the five thermodynamic classes, and the resulting surrogates were used to conduct a global sensitivity analysis. The results show that the highest total sensitivity indices of $\tau_{i g n}$ are those corresponding to uncertainty in group 4, the uncertainty in the enthalpies of class 4 (peroxy radicals), followed by group 5, the uncertainty in the enthalpies of class 5 (hydroperoxide radicals). Additionally, the analysis also revealed that at high initial temperatures, $\tau_{i g n}$ is mostly sensitive to the uncertainty in enthalpies of peroxy radicals (thermodynamic class 4); however, at low initial temperatures, strong joint sensitivity of the uncertainty in enthalpies of thermodynamic classes 4 and 5 is observed.

Finally, we considered simultaneous variability in the four rate rules from [36] and thermodynamic classes 4 and 5, over an eight-dimensional space canonical random variables parameterizing the associated parameters. A LASSO methodology, with latin hypercube sampling, was used to build functionals representation of $\tau_{i g n}$. Results of the Sobol decomposition of the variance revealed that uncertainty in the thermodynamic properties, specifically the enthalpies of thermodynamic class 4 , has a pronounced effect on the variability in $\tau_{i g n}$. Uncertainty in thermodynamic properties are as important as uncertainty in kinetic rates especially in the intermediate temperature range. Hence, uncertainty in thermodynamic parameters should generally be addressed in the development and calibration of reaction models.

\section{Acknowledgments}

The research reported in this publication was supported by King Abdullah University of Science and Technology (KAUST). The authors are grateful to Shimaa Gamil for helpful discussions. 


\section{Appendix A. Reaction Classes}

This appendix provides a table listing the reaction classes for $n$-butanol, as adapted from [47]. 


\begin{tabular}{|c|c|}
\hline Reaction Class & Name \\
\hline 1 & Unimolecular fuel decomposition \\
\hline 2 & H-atom abstraction from the fuel \\
\hline 3 & Fuel radical decomposition \\
\hline 4 & Fuel radical isomerization \\
\hline 5 & $\begin{array}{l}\text { H-atom abstraction reactions from enols (i.e. unsatu- } \\
\text { rated alcohols) }\end{array}$ \\
\hline 6 & $\begin{array}{l}\text { Enol - Keto tautomerizations and isomerizations cat- } \\
\text { alyzed by } \mathrm{H}, \mathrm{HO}_{2} \text { and formic acid }\end{array}$ \\
\hline 7 & Addition of $\mathrm{H}$ radicals to enols \\
\hline 8 & Enol radical decomposition \\
\hline 9 & Unimolecular decomposition of enols \\
\hline 10 & $\begin{array}{l}\text { Reaction of } \mathrm{O}_{2} \text { to } 1 \text {-hydroxybutyl radicals to directly } \\
\text { form an aldehyde/ketone }+\mathrm{HO}_{2}\end{array}$ \\
\hline 11 & Addition of $\mathrm{O}_{2}$ to fuel radicals $\left(\mathrm{R}+\mathrm{O}_{2}=\mathrm{ROO}\right)$ \\
\hline 12 & $\mathrm{R}+\mathrm{ROO}=\mathrm{RO}+\mathrm{RO}$ \\
\hline 13 & $\mathrm{R}+\mathrm{HO}_{2}=\mathrm{RO}+\mathrm{OH} 13$ \\
\hline 14 & $\mathrm{R}+\mathrm{CH}_{3} \mathrm{O}_{2}=\mathrm{RO}+\mathrm{CH}_{3} \mathrm{O}$ \\
\hline 15 & $\begin{array}{l}\mathrm{ROO} \text { radical isomerization }(\mathrm{ROO}=\mathrm{QOOH}) \text { including } \\
\text { Waddington type reaction mechanism }\end{array}$ \\
\hline 16 & Concerted eliminations $\left(\mathrm{ROO}=\mathrm{enol}+\mathrm{HO}_{2}\right)$ \\
\hline 17 & $\mathrm{ROO}+\mathrm{HO}_{2}=\mathrm{ROOH}+\mathrm{OH}$ \\
\hline 18 & $\mathrm{ROO}+\mathrm{H}_{2} \mathrm{O}_{2}=\mathrm{ROOH}+\mathrm{HO}_{2}$ \\
\hline 19 & $\mathrm{ROO}+\mathrm{CH}_{3} \mathrm{O}_{2}=\mathrm{RO}+\mathrm{CH}_{3} \mathrm{O}+\mathrm{O}_{2}$ \\
\hline 20 & $\mathrm{ROO}+\mathrm{ROO}=\mathrm{RO}+\mathrm{RO}+\mathrm{O}_{2}$ \\
\hline 21 & $\mathrm{ROOH}=\mathrm{RO}+\mathrm{OH}$ \\
\hline 22 & RO decomposition \\
\hline 23 & Formation of epoxy alcohols via cyclization \\
\hline 24 & $\begin{array}{l}\text { QOOH }=\text { enol }+\mathrm{HO}_{2} \text { (radical site beta to } \mathrm{OOH} \\
\text { group) }\end{array}$ \\
\hline 25 & $\begin{array}{l}\text { QOOH }=\text { alkene/enol }+ \text { carbonyl }+\mathrm{OH} \text { (radical site } \\
\text { gamma to OOH group) }\end{array}$ \\
\hline 26 & Addition of $\mathrm{O}_{2}$ to $\mathrm{QOOH}\left(\mathrm{QOOH}+\mathrm{O}_{2}=\mathrm{OOQOOH}\right)$ \\
\hline 27 & $\begin{array}{l}\text { Reaction of } \mathrm{O}_{2} \text { with 1-hydroxybutylhydroperoxide } \\
\text { radicals }\end{array}$ \\
\hline 28 & $\begin{array}{l}\text { Isomerization of OOQOOH and formation of car- } \\
\text { bonyl alkylhydroxy hydroperoxides and } \mathrm{OH} \text { including } \\
\text { Waddington type reactions mechanism }\end{array}$ \\
\hline 29 & $\begin{array}{l}\text { Decomposition of carbonyl alkylhydroxy hydroperox- } \\
\text { ides to form oxygenated radical species and } \mathrm{OH}\end{array}$ \\
\hline 30 & Epoxy alcohol reactions with $\mathrm{OH}$ and $\mathrm{HO}_{2}$ \\
\hline
\end{tabular}

Table A.3: Reaction classes involved in the rate rules for n-butanol mechanism. 


\section{References}

[1] R. Kee, F. M. Rupley, J. A. Miller, M. Coltrin, J. Grcar, E. Meeks, CHEMKIN-PRO, 15105, Reaction Design, San Diego, 2010.

[2] D. G. Goodwin, Cantera C++ users guide, California Institute of Technology (2002).

[3] C. Safta, H. Najm, O. Knio, TChem - A Software Toolkit for the Analysis of Complex Kinetic Models, Report No. SAND2011-3282, Sandia National Laboratories, Livermore, CA, USA (2011).

[4] A. Alexanderian, O. Le Maître, H. Najm, M. Iskandarani, O. Knio, Multiscale Stochastic Preconditioners in Non-intrusive Spectral Projection, SIAM J. Sci. Comput. 50 (2012) 306-340.

[5] D. Kim, F. Rizzi, K. Cheng, J. Han, F. Bisetti, O. Knio, Uncertainty quantification of ion chemistry in lean and stoichiometric homogenous mixtures of methane, oxygen, and argon, Combust. Flame 162 (2015) $2904-2915$.

[6] J. Prager, H. N. Najm, J. Zador, Uncertainty quantification in the ab initio rate-coefficient calculation for the $\mathrm{CH}_{3} \mathrm{CH}(\mathrm{OH}) \mathrm{CH}_{3}+\mathrm{OH} \longrightarrow$ $\mathrm{CH}_{3} \mathrm{C}(\mathrm{OH}) \mathrm{CH}_{3}+\mathrm{H}_{2} \mathrm{O}$ reaction, Proc. Combust. Inst. 34 (2013) 583590.

[7] M. T. Reagan, H. Najm, P. Pebay, O. Knio, R. Ghanem, Quantifying uncertainty in chemical systems modeling, Int. J. Chem. Kinet. 37 (2005) 368-382.

[8] H. Najm, R. Berry, C. Safta, K. Sargsyan, B. Debusschere, Data-Free Inference of Uncertain Parameters in Chemical Models, Int. J. Uncertain. Quantif. 4 (2014) 111-132.

[9] J. Kalyanaraman, Y. Kawajiri, R. Lively, M. Realff, Uncertainty Quantification via Bayesian Inference Using Sequential Monte Carlo Methods for $\mathrm{CO}_{2}$ Adsorption Process, AIChE Journal 62 (2016) 3352-3368.

[10] K. Miki, M. Panesi, E. Prudencio, S. Prudhomme, Estimation of the nitrogen ionization reaction rate using electric arc shock tube data and Bayesian model analysis, Phys. Plasmas 19 (2012) 023507.

[11] S. Mosbach, J. Hong, G. Brownbridge, M. Kraft, S. Gudiyella, K. Brezinsky, Bayesian Error Propagation for a Kinetic Model of n-Propylbenzene Oxidation in a Shock Tube, Int. J. Chem. Kinet. 46 (2014) 389-404. 
[12] K. Miki, S. Cheung, E. Prudencio, P. Varghese, Bayesian uncertainty quantification of recent shock tube determinations of the rate coefficient of reaction $\mathrm{H}+\mathrm{O}_{2} \rightarrow \mathrm{OH}+\mathrm{O}$, Int. J. Chem. Kinet. 44 (2012) 586-597.

[13] K. Miki, M. Panesi, E. Prudencio, S. Prudhomme, Probabilistic models and uncertainty quantification for the ionization reaction rate of atomic Nitrogen, J. Comput. Phys. 231 (2012) 3871-3886.

[14] S. Mosbach, A. Braumann, P. Man, C. Kastner, G. Brownbridge, M. Kraft, Iterative improvement of Bayesian parameter estimates for an engine model by means of experimental design, Combust. Flame 159 (2012) 1303-1313.

[15] D. Kim, I. El Gharamti, M. Hantouche, A. E. Elwardany, A. Farooq, F. Bisetti, O. Knio, A hierarchical method for Bayesian inference of rate parameters from shock tube data: Application to the study of the reaction of hydroxyl with 2-methylfuran, Combust. Flame 184 (2017) $55-67$.

[16] J. Prager, H. Najm, K. Sargsyan, C. Safta, W. Pitz, Uncertainty quantification of reaction mechanisms accounting for correlations introduced by rate rules and fitted Arrhenius parameters, Combust. Flame 160 (2013) 1583-1593.

[17] T. Nagy, T. Turányi, Determination of the uncertainty domain of the Arrhenius parameters needed for the investigation of combustion kinetic models, Reliability Engineering \& System Safety 107 (2012) 29-34.

[18] T. Nagy, T. Turányi, Uncertainty of Arrhenius parameters, Int. J. Chem. Kinet. 43 (2011) 359-378.

[19] I. M. Sobol, Global sensitivity indices for nonlinear mathematical models and their Monte Carlo estimates, Math. Comput. Simulat. 55 (2001) $271-280$.

[20] I. M. Sobol', On sensitivity estimation for nonlinear mathematical models, Matematicheskoe Modelirovanie 2 (1990) 112-118.

[21] B. Sudret, Global sensitivity analysis using polynomial chaos expansions, Reliab. Eng. Syst. Safe. 93 (2008) 964-979.

[22] T. Crestaux, O. Le Maître, J.-M. Martinez, Polynomial chaos expansion for sensitivity analysis, Reliab. Eng. Syst. Safe. 94 (2009) 1161-1172. 
[23] A. Alexanderian, J. Winokur, I. Sraj, A. Srinivasan, M. Iskandarani, W. C. Thacker, O. M. Knio, Global sensitivity analysis in an ocean general circulation model: a sparse spectral projection approach, Computat. Geosci. 16 (2012) 757-778.

[24] Y. Marzouk, H. Najm, Dimensionality reduction and polynomial chaos acceleration of Bayesian inference in inverse problems, J. Comput. Phys. 228 (2009) 1862-1902.

[25] F. Cailliez, P. Pernot, Statistical approaches to forcefield calibration and prediction uncertainty in molecular simulation, J. Chem. Phys. 134 (2011) 054124.

[26] K. Sargsyan, H. Najm, R. Ghanem, On the Statistical Calibration of Physical Models, Int. J. Chem. Kinet. 47 (2015) 246-276.

[27] A. Burcat, B. Ruscic, Third millennium ideal gas and condensed phase thermochemical database for combustion, Technion-Israel Institute of Technology, 2001.

[28] J. Bromly, F. Barnes, S. Muris, X. You, B. Haynes, Kinetic and thermodynamic sensitivity analysis of the NO-sensitised oxidation of methane, Combustion science and technology 115 (1996) 259-296.

[29] T. Turányi, L. Zalotai, S. Dóbé, T. Bérces, Effect of the uncertainty of kinetic and thermodynamic data on methane flame simulation results, Physical Chemistry Chemical Physics 4 (2002) 2568-2578.

[30] I. G. Zsély, J. Zádor, T. Turányi, Uncertainty analysis of updated hydrogen and carbon monoxide oxidation mechanisms, Proc. Combust. Inst. 30 (2005) 1273-1281.

[31] J. Zádor, I. G. Zsély, T. Turányi, M. Ratto, S. Tarantola, A. Saltelli, Local and global uncertainty analyses of a methane flame model, J. Phys. Chem. A 109 (2005) 9795-9807.

[32] I. G. Zsély, J. Zádor, T. Turányi, Uncertainty analysis of NO production during methane combustion, International Journal of Chemical Kinetics 40 (2008) 754-768.

[33] F. vom Lehn, L. Cai, H. Pitsch, Sensitivity analysis, uncertainty quantification, and optimization for thermochemical properties in chemical kinetic combustion models, Proc. Combust. Inst. 37 (2019) 771-779. 
[34] F. vom Lehn, L. Cai, H. Pitsch, Impact of thermochemistry on optimized kinetic model predictions: Auto-ignition of diethyl ether, Combust. Flame 210 (2019) 454-466.

[35] F. vom Lehn, L. Cai, H. Pitsch, Investigating the impacts of thermochemical group additivity values on kinetic model predictions through sensitivity and uncertainty analyses, Combust. Flame 213 (2020) 394408.

[36] M. Hantouche, S. M. Sarathy, O. M. Knio, Global sensitivity analysis of n-butanol reaction kinetics using rate rules, Combust. Flame 196 (2018) 452-465.

[37] S. Burke, J. Simmie, H. Curran, Critical evaluation of thermochemical properties of $\mathrm{C} 1-\mathrm{C} 4$ species: updated group-contributions to estimate thermochemical properties, Journal of Physical and Chemical Reference Data 44 (2015) 013101.

[38] B. J. McBride, S. Gordon, M. A. Reno, Coefficients for Calculating Thermodynamic and Transport Properties of Individual Species, Technical Report NASA TM-4513, NASA, 1993.

[39] M. Chase, C. Davies, J. Downey Junior, R. McDonald, A. Syverud, E. Valenzuela, JANAF Thermochemical Tables, Journal of Physical and Chemical Reference Data (1985).

[40] E. Lemmon, M. Huber, M. McLinden, NIST Standard Reference Database 23, Reference Fluid Thermodynamic and Transport Properties (REFPROP), version 9.0, National Institute of Standards and Technology, R1234yf. fld file dated December 22 (2010) 2010.

[41] B. Ruscic, R. E. Pinzon, M. L. Morton, N. K. Srinivasan, M.-C. Su, J. W. Sutherland, J. V. Michael, Active thermochemical tables: Accurate enthalpy of formation of hydroperoxyl radical, HO2, J. Phys. Chem. A 110 (2006) 6592-6601.

[42] Active thermochemical tables, https://atct.anl.gov/, 2019.

[43] A. Burcat, B. Ruscic, Third millenium ideal gas and condensed phase thermochemical database for combustion (with update from active thermochemical tables)., Technical Report, Argonne National Lab.(ANL), Argonne, IL (United States), 2005. 
[44] S. W. Benson,Bond energies, Journal of Chemical Education 42 (1965) 502.

[45] S. W. Benson, Thermochemical kinetics: methods for the estimation of thermochemical data and rate parameters, Wiley, 1968.

[46] E. R. Ritter, THERM: a computer code for estimating thermodynamic properties for species important to combustion and reaction modeling, Journal of Chemical Information and Computer Sciences 31 (1991) 400408.

[47] S. M. Sarathy, P. Oßwald, N. Hansen, K. Kohse-Höinghaus, Alcohol combustion chemistry, Prog. Energy Combust. Sci. 44 (2014) 40-102.

[48] O. Le Maître, O. M. Knio, Spectral methods for uncertainty quantification: with applications to computational fluid dynamics, Springer Science \& Business Media, 2010.

[49] P. G. Constantine, M. S. Eldred, E. T. Phipps, Sparse pseudospectral approximation method, Comput. Method. Appl. M. 229 (2012) 1-12.

[50] P. R. Conrad, Y. M. Marzouk, Adaptive Smolyak Pseudospectral Approximations, SIAM J. Sci. Comput. 35 (2013) A2643-A2670.

[51] J. Winokur, P. Conrad, I. Sraj, O. Knio, A. Srinivasan, W. C. Thacker, Y. Marzouk, M. Iskandarani, A priori testing of sparse adaptive polynomial chaos expansions using an ocean general circulation model database, Computat. Geosci. 17 (2013) 899-911.

[52] J. G. Winokur, Adaptive sparse grid approaches to polynomial chaos expansions for uncertainty quantification, Ph.D. thesis, Duke University, 2015 .

[53] D. Kim, F. Rizzi, K. W. Cheng, J. Han, F. Bisetti, O. M. Knio, Uncertainty quantification of ion chemistry in lean and stoichiometric homogenous mixtures of methane, oxygen, and argon, Combust. Flame 162 (2015) 2904-2915.

[54] J. Winokur, D. Kim, F. Bisetti, O. P. Le Maître, O. M. Knio, Sparse pseudo spectral projection methods with directional adaptation for uncertainty quantification, J. Sci. Comput. 68 (2016) 596-623.

[55] R. Tibshirani, Regression shrinkage and selection via the LASSO, Journal of the Royal Statistical Society: Series B (Methodological) 58 (1996) 267-288. 
[56] H. Zou, T. Hastie, Regularization and variable selection via the elastic net, Journal of the Royal Statistical Society: Series B (Statistical Methodology) 67 (2005) 301-320.

[57] J. Friedman, T. Hastie, R. Tibshirani, Regularization paths for generalized linear models via coordinate descent, Journal of Statistical Software 33 (2010) 1.

[58] T. Hastie, R. Tibshirani, J. Friedman, The elements of statistical learning: data mining, inference, and prediction, Springer Science \& Business Media, 2009.

[59] S. Boyd, N. Parikh, E. Chu, Distributed optimization and statistical learning via the alternating direction method of multipliers, Now Publishers Inc, 2011. 